\title{
Patterns of brain degeneration in early-stage relapsing-remitting multiple sclerosis
}

\author{
Rozanna Meijboom ${ }^{a, b}$, Elizabeth N York ${ }^{a, b}$, Agniete Kampaite ${ }^{a, b}$, Mathew A Harris ${ }^{c}$, Nicole White ${ }^{a, b}$, \\ Maria del C Valdés Hernández ${ }^{a, b}$, Michael J Thrippleton ${ }^{a, b}$, Peter Connick ${ }^{a, d}$, David Hunt ${ }^{a}$, Siddharthan \\ Chandran $^{\mathrm{a}, \mathrm{d}}$, Adam D Waldman ${ }^{\mathrm{a}, \mathrm{b}}$, on behalf of the FutureMS Consortium \\ ${ }^{a}$ Centre for Clinical Brain Sciences, University of Edinburgh, UK \\ ${ }^{b}$ Edinburgh Imaging, University of Edinburgh, UK \\ ${ }^{c}$ Department of Psychology, University of Edinburgh, UK \\ ${ }^{d}$ Anne Rowling Regenerative Neurology Clinic, University of Edinburgh, UK
}

\section{Correspondence:}

Prof Adam Waldman

Edinburgh Imaging

Centre for Clinical Brain Sciences, University of Edinburgh

Edinburgh BioQuarter: Chancellors Building

Edinburgh EH16 4SB, United Kingdom

E-mail: Adam.Waldman@ed.ac.uk

Tel: 01312426200 


\section{ABSTRACT}

Recurrent neuroinflammation in relapsing-remitting MS (RRMS) is thought to lead to neurodegeneration, resulting in progressive disability. Repeated magnetic resonance imaging (MRI) of the brain provides non-invasive measures of atrophy over time, a key marker of neurodegeneration. This study investigates regional neurodegeneration of the brain in early-stage RRMS using volumetry and voxel-based morphometry (VBM).

RRMS patients ( $N=354)$ underwent 3T structural MRI at diagnosis and 1-year follow-up, as part of the Scottish multicentre 'FutureMS' study. MRI data were processed using FreeSurfer to derive volumetrics, and FSL for VBM (grey matter (GM) only), to establish patterns of change in GM and normal-appearing white matter (NAWM) over time throughout the cerebrum, cerebellum and brainstem.

Volumetric analyses showed a decrease over time $(q<0.05)$ in bilateral cortical GM and NAWM, multiple subcortical structures, cerebellar GM and the brainstem. Additionally, NAWM and GM volume decreased respectively in the following cortical regions, frontal: 14 out of 28 regions and 17/28; temporal: 18/18 and 15/18; parietal: $14 / 14$ and 11/14; occipital: $7 / 8$ and 8/8. Left GM and NAWM asymmetry was observed in the frontal lobe. GM VBM analysis showed three major clusters of decrease over time: 1) temporal lobe and subcortical areas, 2) cerebellum, 3) anterior cingulum and supplementary motor cortex; and four smaller clusters within the occipital lobe.

Widespread neurodegeneration was observed in early-stage RRMS; particularly in the brainstem, cerebellar GM, and subcortical and occipital-temporal regions. Volumetric and VBM results emphasise different as well as overlapping patterns of longitudinal change, and provide potential response markers for existing therapies and trials of neuroprotective agents. 


\section{Introduction}

Multiple sclerosis (MS) is a neuroinflammatory and neurodegenerative disease affecting two million people worldwide [1-3]. MS prevalence varies geographically and is notably high in Scotland, with a prevalence of 290 cases per 100,000 population [4-6]. Disease progression and severity varies between individuals, and symptoms are diverse, including mobility and vision problems, pain, depression, fatigue and cognitive impairment [7]. Several MS subtypes have been identified, of which relapsing-remitting disease (RRMS) is the most common $[8,9]$. There is currently no cure for MS and treatments targeting the neurodegenerative aspects of MS are limited. More accurate biomarkers of disease progression and improved understanding of disease mechanisms, particularly in terms of neurodegeneration, are required for more suitable treatment of MS. Magnetic resonance imaging (MRI) allows for studying neurodegeneration in vivo and may thus provide such valuable biomarkers of MS severity and progression.

White matter lesions (WMLs) on MRI, reflecting underlying inflammatory demyelinating lesions, are considered an imaging hallmark of RRMS and are required for RRMS diagnosis [10]. Modulating neuroinflammation is also the primary target for currently available disease modifying treatment (DMT) for RRMS. However, these appear to have only a limited effect on reducing associated neurodegenerative processes $[11,12]$. Previous studies have shown that neurodegeneration also plays a prominent role in the disease evolution of RRMS and is importantly already present in the early stages of the disease [13-18]. Early-stage grey matter (GM) atrophy has been observed in specific brain areas, including the cingulate gyrus, precuneus, thalamus, basal ganglia, brainstem and cerebellum [14, 19-21]. Less regional detail appears to be known about WM atrophy in RRMS, but it also occurs in early stages and has been suggested to occur independently of WML development $[13,22,23]$. Importantly, atrophy appears to be a better predictor of clinical disability and deterioration than WMLs [16, 20, 24-34]. This suggests it could be an important target for diseaseslowing treatments. There have indeed been studies investigating the effect of current DMTs on atrophy, suggesting a slowing of neurodegeneration after DMT use [35-40]. More research is required to investigate the effect of current DMTs and possible future neuroprotective therapies on brain atrophy. Such studies would benefit from detailed knowledge of the location and extent of early-stage GM and WM atrophy in RRMS [41].

To our knowledge, current literature does not provide detailed insights into regional WM volume loss in very early-stage RRMS, and only a limited number of studies have examined specific GM volume in early stages of the disease [14, 19-21]. The current study uses data from FutureMS [42], a large multicentre cohort of recently-diagnosed RRMS patients in Scotland, which acquired extensive MR imaging [43] at baseline and one-year follow-up. Importantly, study participants were recruited within six months of diagnosis, enabling early-stage detection of neurodegenerative patterns. In addition, participants were treatment-naive for the baseline study visit, improving detection of brain changes attributed to underlying MS disease mechanisms. Furthermore, FutureMS recruited people with RRMS throughout Scotland, allowing for studying brain degeneration in a cohort representative of the Scottish MS population. The aim of this study was to investigate comprehensive neurodegenerative changes in early-stage RRMS patients, supported by comparison of two different analysis approaches. This allows for identification of brain areas specifically affected by 
medRxiv preprint doi: https://doi.org/10.1101/2021.11.18.21266506; this version posted January 18, 2022. The copyright holder for this preprint (which was not certified by peer review) is the author/funder, who has granted medRxiv a license to display the preprint in perpetuity. It is made available under a CC-BY-NC-ND 4.0 International license.

neurodegeneration, which may provide possible biomarkers of disease progression in terms of atrophy for DMT trials. 


\section{Methods}

\subsection{Participants}

Participants with a recent diagnosis of RRMS according to the 2017 McDonald criteria ( 6 months) [10], were recruited across five neurology sites in Scotland: Aberdeen, Dundee, Edinburgh, Inverness and Glasgow, as part of the FutureMS study [42, 43]. Participants were 18 years or older and had the capacity to provide informed consent. Exclusion criteria were intake of DMTs prescribed prior to baseline assessment, participation in a clinical trial prior to baseline assessment and contraindications for MRI. Study visits took place at baseline (wave 0 [w0])) and 1-year follow-up (w1) and participants underwent brain MRI and expanded-disability status scale (EDSS) assessment at both time points. Full details of the FutureMS study have been previously described in Kearns et al. 2021 [42].

$\mathrm{N}=431$ participants underwent $\mathrm{MR}$ imaging at w0 and $\mathrm{N}=382$ participants underwent $\mathrm{MR}$ imaging at w1. The main reasons for not returning for $w 1$ were not being able to reach participants at the provided contact details or participants having moved away from Scotland and not wanting to travel back. Additionally, the COVID-19 pandemic prematurely terminated w1 visits, which prevented several participants returning for their second visit. Additionally, 77/431 participants were excluded for various reasons (see Figure 1), resulting in $\mathrm{N}=354$ available MRI datasets for analysis.

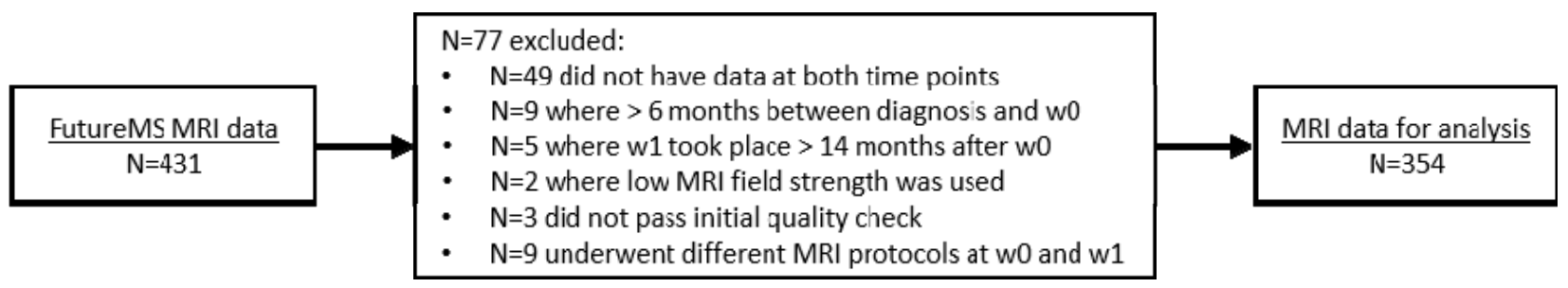

Figure 1. Overview of data exclusions.

All participants provided written informed consent before study entry. The study received ethical approval from the South East Scotland Research Ethics Committee 02 under reference 15/SS/0233 and was conducted in accordance with the Declaration of Helsinki and ICH guidelines on good clinical practice. All data were anonymised with unique study identifiers.

\subsection{MR image acquisition}

MR image acquisition was performed across four sites in Scotland using comparable 3T MRI systems (Siemens in Glasgow, Dundee and Edinburgh; Philips in Aberdeen). Protocol harmonisation was implemented during the course of the study to increase between-site comparability and facilitate image analysis. Importantly, each participant underwent both MRI scans at the same centre using the same protocol. All participants underwent T1-weighted, T2-weighted, and 2D and 3D FLAIR imaging. Full details have been previously described in Meijboom et al. (2021) [43] (see supplement Table 1 for an overview of all MR parameters).

\subsection{MR image processing}


Image processing methods have been previously described in full in Meijboom et al. (2021) [43] and are briefly summarised in the sections below.

\subsubsection{Registration and ICV}

All images were registered to the $\mathrm{T} 1 \mathrm{~W}$ image with a rigid body transformation (degrees of freedom $=$ 6) using FSL FLIRT (FSL v6.0.1) [44, 45] separately for each time point. Brain tissue was isolated using FSL BET2 (FSL v6.0.1) [46], followed by manual editing of the resulting w0 intracranial image using ITK-SNAP v3.8.0 [47]. For each participant, the edited w0 intracranial image was registered to the w1 T1W image, to avoid within-subject variability between time points. Intracranial volume (ICV) was extracted using fslstats (FSL6.0.1).

\subsubsection{WML segmentation}

Hyperintense voxels on 2D FLAIR were identified by thresholding intensity values to 1.69 SDs > mean, using an adjusted method from Zhan et al. (2014) [48]. Resulting hyperintense areas unlikely to reflect pathology were removed using a pre-defined lesion distribution template [49], followed by Gaussian smoothing. Resulting WML masks were manually edited using ITK-SNAP [47]. WML volumes were extracted using fslstats and expressed as a ratio of ICV (r-ICV) to correct for head size.

\subsubsection{Tissue segmentation}

Tissue segmentation was performed on $\mathrm{T} 1 \mathrm{~W}$ and $\mathrm{T} 2 \mathrm{~W}$ images using the longitudinal processing stream [50] in FreeSurfer v6.0 (http://surfer.nmr.mgh.harvard.edu/) with default settings, the Desikan-Kiliany atlas [51] and the edited ICV as brain mask. Freesurfer output was manually edited by a trained neuroscientist where necessary using FreeView v2.0 (FreeSurfer v6.0). WML masks were then subtracted from the resulting tissue segmentations using fslmaths (FSL6.0.1), to create final tissue masks. Global and regional tissue volumes (see Table 1) were calculated from the final tissue masks using fslstats, and subsequently expressed as r-ICV to correct for head size.

Table 1. Global and regional GM/WM and subcortical areas. Left and right hemisphere were separately included for all areas, excluding the brainstem.

\begin{tabular}{|c|c|c|c|c|c|c|}
\hline $\begin{array}{l}\sum_{0} \\
\frac{0}{2} \\
\frac{2}{0} \\
\frac{1}{3} \\
\frac{\pi}{0} \\
\frac{0}{0}\end{array}$ & \multicolumn{2}{|l|}{$\begin{array}{l}\text { Brainstem } \\
\text { Cortical GM } \\
\text { Cerebellar GM } \\
\text { Cerebral WM } \\
\text { Cerebellar WM }\end{array}$} & 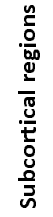 & \multicolumn{3}{|l|}{$\begin{array}{l}\text { Amygdala } \\
\text { Basal ganglia } \\
\text { Hippocampus } \\
\text { Nucleus accumbens } \\
\text { Thalamus } \\
\text { Ventral diencephalon }\end{array}$} \\
\hline 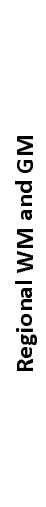 & $\begin{array}{l}\text { Frontal } \\
\text { Superior frontal } \\
\text { Caudal middle frontal } \\
\text { Rostral middle frontal } \\
\text { Pars opercularis } \\
\text { Pars triangularis } \\
\text { Pars orbitalis } \\
\text { Lateral orbitofrontal } \\
\text { Medial orbitofrontal } \\
\text { Precentral } \\
\text { Paracentral } \\
\text { Frontal pole } \\
\text { Caudal anterior cingulate } \\
\text { Rostral anterior cingulate }\end{array}$ & \begin{tabular}{l}
\multicolumn{1}{c}{ Parietal } \\
Superior parietal \\
Inferior parietal \\
Supramarginal \\
Postcentral \\
Precuneus \\
Posterior cingulate \\
Isthmus cingulate
\end{tabular} & $\begin{array}{l}\text { Sup } \\
\text { Mid } \\
\text { Infe } \\
\text { Sup } \\
\text { Fusi } \\
\text { Trar } \\
\text { Ento } \\
\text { Tem } \\
\text { Para }\end{array}$ & $\begin{array}{l}\text { Temporal } \\
\text { rior temporal } \\
\text { le temporal } \\
\text { ior temporal } \\
\text { rior temporal sulcus banks } \\
\text { orm } \\
\text { sverse temporal } \\
\text { rhinal } \\
\text { ooral Pole } \\
\text { nippocampal }\end{array}$ & $\begin{array}{l}\qquad \text { Occipital } \\
\text { Lateral Occipital } \\
\text { Lingual } \\
\text { Cuneus } \\
\text { Pericalcarine }\end{array}$ & Insula \\
\hline
\end{tabular}




\subsubsection{Voxel-based morphometry}

Longitudinal voxel-based morphometry (VBM), applying a voxel-wise comparison of local GM concentration between $w 0$ and $w 1$, was performed using the FSL VBM pipeline (FSL6.0.1; http://fsl.fmrib.ox.ac.uk/fsl/fslwiki/FSLVBM) [52-55]. It was performed for GM only, because GM VBM is a more commonly used and accepted method (e.g. a WM VBM pipeline is not implemented in FSL). The first step of the VBM pipeline (i.e. brain extraction) was omitted, as we were able to use the previously created intracranial brain images, as described above. In step two, GM, WM and CSF were segmented from T1W images and the study-specific GM template was created. Specifically, all subject GM images at both time points were affine-registered to the GM ICBM-152 template, and then concatenated and averaged to create a study-specific GM template. The subject GM images were then non-linearly registered to this template, and concatenated and averaged again to then create a final study-specific GM template in standard space $\left(2 \times 2 \times 2 \mathrm{~mm}^{3}\right.$ resolution). In the last step, subject GM at both time points was then non-linearly registered to this study-specific template, after which a Jacobian modulation was applied, resulting in modulated GM images for each time point per subject.

As an additional step, to allow for longitudinal VBM analysis, we subtracted the modulated GM images for w1 from those at w0 using fslmaths, resulting in a GM difference file for each subject. Modulated GM difference files were then smoothed with a Gaussian size 2 kernel using fslmaths, and concatenated using fslmerge (FSL6.0.1) to form a final 4D group GM difference image for statistical analysis.

\subsection{Statistical analyses}

\subsubsection{Volumetrics}

Statistical analysis for tissue volumes was performed using R v4.0.2 [56] and package ImerTest [57], with further packages ggplot2 [58] and lattice [59] used to create figures. A linear mixed-effects model was applied for each tissue volume (Table 1) with time point (w0, w1) as regressor of interest and age, sex, imaging site, WML change ( $w 1-w 0)$ and DMT status at $w 1$ as covariates. For each outcome variable, extreme outliers (>3 SD) as well as participants with missing data (for outcome and/or covariates) at either time point were excluded and subsequently scaled before being entered into the linear model. FDR correction was performed to adjust $p$-values for multiple comparisons, with corrected $p$-values ( $q$-values) considered significant at $q<0.05$.

\subsubsection{Voxel-based morphometry}

FSL Randomise (FSL v6.0.1) [60] was used to perform nonparametric permutation analysis on the VBM output. A general linear model (GLM) design matrix was created with GM difference, age, sex, imaging site, DMT status at w1 and subject-specific WML mask as explanatory variables (EV). EVs were recentered to zero where appropriate.

WMLs were included as EVs to ensure their exclusion from the GM images. Subject-specific WML EVs were created by a) registering all subject-specific WML masks at w0 and w1 to the subject's modulated GM segmentation image at respectively w0 and $w 1$, with the VBM transformation matrix that was created for registration of the native T1W to the group-specific template (fs/maths), and $b$ ) using FSL tool 'setup_masks' (FSL6.0.1; https://fsl.fmrib.ox.ac.uk/fsl/fslwiki/Randomise/UserGuide) 
medRxiv preprint doi: https://doi.org/10.1101/2021.11.18.21266506; this version posted January 18, 2022. The copyright holder for this preprint

(which was not certified by peer review) is the author/funder, who has granted medRxiv a license to display the preprint in perpetuity.

$$
\text { It is made available under a CC-BY-NC-ND } 4.0 \text { International license. }
$$

to generate a concatenated 4D subject-specific WML image from the step a output images, as well as add a WML EV for each subject separately to the design matrix.

One t-contrast was defined, which assessed GM change over time, corrected for the remaining EV's. The 'randomise' function was run using 5000 permutations, and with threshold-free cluster enhancing (TFCE) [61] to perform a voxel-wise analysis with a specific focus on voxel clusters. Cluster (FSL6.0.1) was used to extract resulting clusters and atlasquery (FSL v6.0.1) was used to obtain labels for the included anatomical regions. Results were reported for voxels at $p<0.001$ and family-wise error (FWR) corrected for multiple comparisons. 


\section{Results}

\subsection{Demographics}

Data from $\mathrm{N}=315$ participants were used for tissue volume analysis and data from $\mathrm{N}=351$ were used for VBM analysis. Specifically, for tissue volume analysis 39/354 datasets were excluded after FreeSurfer output quality check and for VBM 3/354 datasets were excluded for data processing purposes. In addition, for the tissue volume dataset, for participants where segmentation failed for one or a small number of areas only (usually subcortical), the appropriate areas were excluded from analysis, but the remaining data of the participant was included in analysis. See Table 2 for participant demographics for each analysis type.

Table 2. Participant demographics.

\begin{tabular}{|c|c|c|c|c|c|c|}
\hline $\begin{array}{l}\text { Type of } \\
\text { analysis }\end{array}$ & $\mathbf{N}$ & Gender & $\begin{array}{l}\text { Mean age at } \\
\text { wo (SD) }\end{array}$ & $\begin{array}{l}\text { Median EDSS at } \\
\text { wo (IQR) }\end{array}$ & $\begin{array}{c}\text { Mean diagnosis to wo } \\
\text { in days (SD) }\end{array}$ & DMT use \\
\hline Tissue volumes & 315 & $235 \mathrm{~F}$ & $38.18(10.21)$ & $2(1.5)$ & $63.77(39.12)$ & w0: yes $=0 \mid$ w1: yes $=224 \& N A=8$ \\
\hline VBM & 351 & $262 \mathrm{~F}$ & $38.22(10.38)$ & $2(1.5)$ & $64.02(39.04)$ & w0: yes $=0 \mid$ w1: yes $=252 \& N A=13$ \\
\hline
\end{tabular}

\subsection{Global GM/WM, subcortical and whole-brain volumes}

Whole-brain, brainstem and left and right cerebral GM and WM, cerebellar GM, brainstem, amygdala, basal ganglia, hippocampus, nucleus accumbens, thalamus and ventral diencephalon volumes significantly $(q<0.05)$ decreased over time, whereas left and right cerebellar WM did not significantly ( $q>0.05$ ) change over time (Table 3, Figure 2 ). 
medRxiv preprint doi: https://doi.org/10.1101/2021.11.18.21266506; this version posted January 18, 2022. The copyright holder for this preprint (which was not certified by peer review) is the author/funder, who has granted medRxiv a license to display the preprint in perpetuity.

It is made available under a CC-BY-NC-ND 4.0 International license .

Table 3. Global GM/NAWM, subcortical and whole-brain volumes results for change over time (w1-w0) as assessed with a linear mixedeffects model, corrected for age, sex, imaging site, DMT status at W1 and WML change. Mean and SD are shown for raw volumes ( $r-I C V$ ),

\begin{tabular}{|c|c|c|c|c|c|c|c|c|c|c|c|}
\hline & B & SE & df & $\mathrm{t}$ & $p$-value & $\mathrm{Cl} 2.5$. & Cl 97.5. & Mean wo & Mean w1 & SD w0 & SD w1 \\
\hline Accumbens L & -0.0564 & 0.0213 & 306 & -2.6441 & 0.0086 & -0.0983 & -0.0145 & 0.0004 & 0.0004 & 0.0001 & 0.0001 \\
\hline Accumbens $\mathrm{R}$ & -0.0797 & 0.0229 & 284 & -3.4809 & 0.0006 & -0.1246 & -0.0347 & 0.0004 & 0.0004 & 0.0001 & 0.0001 \\
\hline Amygdala L & -0.1003 & 0.0228 & 305 & -4.3966 & 0.0000 & -0.1451 & -0.0555 & 0.0010 & 0.0010 & 0.0001 & 0.0001 \\
\hline Amygdala R & -0.1484 & 0.0224 & 306 & -6.6139 & 0.0000 & -0.1924 & -0.1043 & 0.0012 & 0.0011 & 0.0001 & 0.0001 \\
\hline Basal Ganglia L & -0.1545 & 0.0198 & 305 & -7.7884 & 0.0000 & -0.1934 & -0.1155 & 0.0065 & 0.0064 & 0.0008 & 0.0008 \\
\hline Basal Ganglia R & -0.1632 & 0.0204 & 306 & -8.0073 & 0.0000 & -0.2032 & -0.1232 & 0.0065 & 0.0064 & 0.0008 & 0.0008 \\
\hline Brainstem & -0.0654 & 0.0139 & 305 & -4.7223 & 0.0000 & -0.0926 & -0.0382 & 0.0132 & 0.0131 & 0.0014 & 0.0014 \\
\hline GM cerebellar L & -0.0537 & 0.0119 & 305 & -4.5056 & 0.0000 & -0.0772 & -0.0303 & 0.0341 & 0.0339 & 0.0040 & 0.0039 \\
\hline GM cerebellar $\mathrm{R}$ & -0.0624 & 0.0132 & 305 & -4.7386 & 0.0000 & -0.0882 & -0.0365 & 0.0346 & 0.0344 & 0.0039 & 0.0039 \\
\hline GM cortical L & -0.0896 & 0.0172 & 305 & -5.1992 & 0.0000 & -0.1234 & -0.0558 & 0.1549 & 0.1541 & 0.0133 & 0.0132 \\
\hline GM cortical R & -0.0626 & 0.0172 & 306 & -3.6346 & 0.0003 & -0.0964 & -0.0288 & 0.1551 & 0.1545 & 0.0131 & 0.0131 \\
\hline Hippocampus L & -0.1067 & 0.0186 & 305 & -5.7223 & 0.0000 & -0.1433 & -0.0701 & 0.0027 & 0.0026 & 0.0003 & 0.0003 \\
\hline Hippocampus R & -0.1122 & 0.0176 & 303 & -6.3582 & 0.0000 & -0.1468 & -0.0776 & 0.0028 & 0.0028 & 0.0007 & 0.0007 \\
\hline NAWM cerebellar L & -0.0182 & 0.0171 & 304 & -1.0644 & 0.2880 & -0.0518 & 0.0154 & 0.0097 & 0.0097 & 0.0056 & 0.0054 \\
\hline NAWM cerebellar R & 0.0091 & 0.0165 & 305 & 0.5507 & 0.5822 & -0.0233 & 0.0415 & 0.0091 & 0.0091 & 0.0012 & 0.0012 \\
\hline NAWM cerebral L & -0.1394 & 0.0122 & 304 & -11.3883 & 0.0000 & -0.1635 & -0.1154 & 0.1403 & 0.1388 & 0.0137 & 0.0140 \\
\hline NAWM cerebral R & -0.1274 & 0.0120 & 306 & -10.6280 & 0.0000 & -0.1509 & -0.1039 & 0.1402 & 0.1388 & 0.0135 & 0.0139 \\
\hline Thalamus L & -0.1170 & 0.0118 & 306 & -9.9065 & 0.0000 & -0.1402 & -0.0938 & 0.0050 & 0.0049 & 0.0074 & 0.0073 \\
\hline Thalamus R & -0.1058 & 0.0108 & 304 & -9.7489 & 0.0000 & -0.1271 & -0.0845 & 0.0044 & 0.0044 & 0.0005 & 0.0005 \\
\hline Ventral DC L & -0.0794 & 0.0177 & 304 & -4.4856 & 0.0000 & -0.1142 & -0.0447 & 0.0026 & 0.0025 & 0.0003 & 0.0003 \\
\hline Ventral DC R & -0.1328 & 0.0189 & 284 & -7.0208 & 0.0000 & -0.1699 & -0.0957 & 0.0024 & 0.0024 & 0.0007 & 0.0007 \\
\hline Whole-brain & -0.1023 & 0.0150 & 305 & -6.8369 & 0.0000 & -0.1316 & -0.0729 & 0.7412 & 0.7374 & 0.0374 & 0.0378 \\
\hline \multicolumn{12}{|c|}{$\begin{array}{l}B=\text { standardised beta value, } S E=\text { standard error, } d f=\text { degrees of freedom, } C l=\text { confidence interval for beta value, } S D=\text { standard deviation, } \\
\text { wO=baseline, } w 1=1-y e a r \text { follow-up, } L=l e f t, R=r i g h t, G M=\text { grey matter, } N A W M=\text { normal-appearing white matter, } W M L=\text { white matter lesion, } \\
D C=\text { diencephalon, } r-I C V=\text { ratio of intracranial volume. }\end{array}$} \\
\hline
\end{tabular}

without covariate correction.

\subsection{Regional cortical GM and cerebral WM}

Regional GM and NAWM volume decrease ( $q<0.05$ ) was observed in most regions and predominantly in the temporal, parietal and occipital lobe. GM volume decreased over time in 15/18 temporal regions, 15/26 frontal regions, 11/14 parietal regions, $8 / 8$ occipital regions and the bilateral insula. NAWM volume decreased over time in 18/18 temporal regions, 13/26 frontal regions, 14/14 parietal regions, 7/8 occipital regions and the insula (L). More GM and NAWM regions showed volume loss in the left than in the right hemisphere, particularly in the frontal lobe. See

Figures 2-3 and supplement Table 2. 


\section{It is made available under a CC-BY-NC-ND 4.0 International license .}

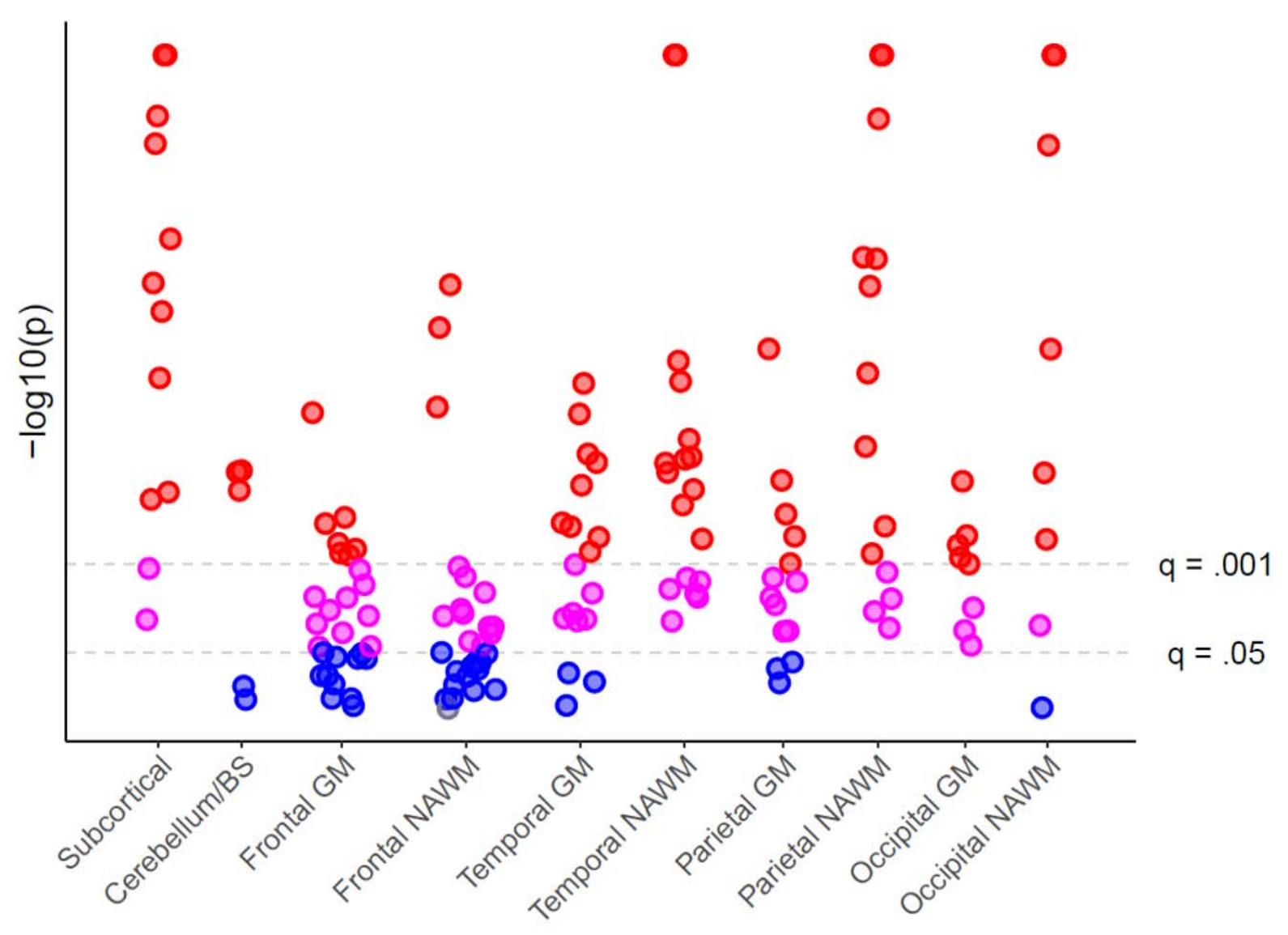

Figure 2. Manhattan plot of longitudinal brain volume change. Each point represents a tissue region within the given brain area category ( $x$-axis). P-values were inverse log transformed ( $y$-axis). Insignificant $p$-values $(p>0.05)$ are shown in blue. Significant $(p<0.05)$ FDR corrected $p$-values at $q=0.05$ are shown in pink, and in red for $q=0.001$. Regardless of significance, the direction of all effects - but one frontal NAWM area (in grey) - showed a longitudinal volume decrease. BS=brainstem, GM=grey matter, NAWM=normal-appearing white matter, FDR=false discovery rate. 


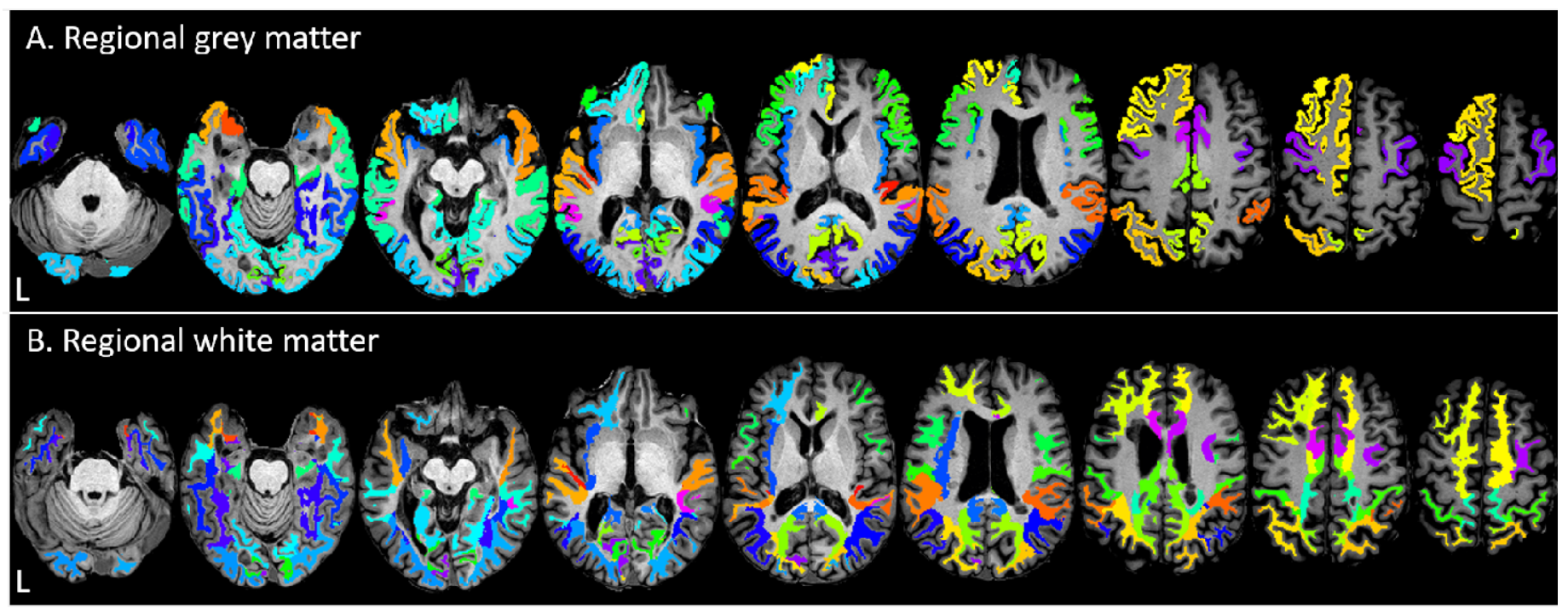

Figure 3. For illustration purposes, regional GM (A) and NAWM (B) regions with significant volume decrease (w1-w0; $q<0.05$ ) are shown on an example subject's axial T1W image. Colours were chosen to emphasise borders between regions and have no further meaning in terms of results. This figure was created using MRIcron (https://www.nitrc.org/projects/mricron).

\subsection{Voxel-based GM change}

Twelve clusters of various sizes (Table 5) showed a change in local concentration of GM over time. The largest clusters were centred within 1) the temporal lobe and subcortical areas, 2) cerebellum, 3) anterior cingulum and supplementary motor cortex. Additional smaller clusters were also observed in the temporal lobe and cerebellum. Furthermore, four smaller clusters were observed in the occipital lobe, as well as one cluster in the posterior frontal lobe and one in the parietal supramarginal and angular gyrus. See Figure 4.

Table 5. VBM cluster results (cluster-size $>20, \mathbf{p}_{\text {corrected }}<0.001$ ) for GM change over time (w1-w0) in RRMS (N=351).

\begin{tabular}{|c|c|c|c|c|c|c|c|c|c|}
\hline $\begin{array}{c}\text { Cluste } \\
\mathbf{r} \\
\text { Index } \\
\end{array}$ & Voxels & $\begin{array}{c}\text { MAX } \\
X \\
\text { (mm) }\end{array}$ & $\begin{array}{l}\text { MAX Y } \\
(\mathrm{mm})\end{array}$ & $\begin{array}{l}\text { MAX Z } \\
(\mathrm{mm})\end{array}$ & $\begin{array}{l}\operatorname{COG} x \\
(\mathrm{~mm})\end{array}$ & $\begin{array}{l}\operatorname{COG} Y \\
(\mathrm{~mm})\end{array}$ & $\begin{array}{l}\text { COG Z } \\
(\mathrm{mm})\end{array}$ & $\begin{array}{l}\text { MAX anatomical } \\
\text { location }\end{array}$ & $\begin{array}{c}\text { COG anatomical } \\
\text { location }\end{array}$ \\
\hline 1 & 7415 & 34 & 4 & -44 & 3.03 & -1.47 & -4.59 & $\begin{array}{l}\text { Temporal Pole, Anterior } \\
\text { Temporal Fusiform } \\
\text { Gyrus, } \\
\text { Anterior Inferior } \\
\text { Temporal Gyrus }\end{array}$ & Right thalamus \\
\hline 2 & 2882 & 20 & -64 & -52 & 1.76 & -65.2 & -32.1 & Cerebellum & Cerebellum \\
\hline 3 & 794 & 0 & 22 & 20 & -0.111 & -1.98 & 45.5 & Anterior Cingulate Gyrus & $\begin{array}{l}\text { Anterior Cingulate } \\
\text { Gyrus, Supplementary } \\
\text { Motor Cortex }\end{array}$ \\
\hline 4 & 83 & 42 & 12 & 26 & 42.1 & 9.71 & 30.8 & $\begin{array}{l}\text { Inferior/Middle Frontal } \\
\text { Gyrus, Precentral Gyrus }\end{array}$ & $\begin{array}{l}\text { Inferior/Middle Frontal } \\
\text { Gyrus, Precentral Gyrus }\end{array}$ \\
\hline 5 & 74 & -24 & -76 & -12 & -22.8 & -73.9 & -11.4 & $\begin{array}{l}\text { Occipital Fusiform Gyrus, } \\
\text { Lateral Occipital Gyrus, } \\
\text { Lingual Gyrus }\end{array}$ & $\begin{array}{l}\text { Occipital Fusiform Gyrus, } \\
\text { Lingual Gyrus }\end{array}$ \\
\hline 6 & 62 & 34 & -96 & -10 & 27.1 & -97.8 & -5.35 & $\begin{array}{l}\text { Occipital Pole, lateral } \\
\text { occipital cortex }\end{array}$ & Occipital Pole \\
\hline 7 & 39 & 14 & -98 & 18 & 10.7 & -95.4 & 22.9 & Occipital Pole & Occipital Pole \\
\hline
\end{tabular}


medRxiv preprint doi: https://doi.org/10.1101/2021.11.18.21266506; this version posted January 18, 2022. The copyright holder for this preprint (which was not certified by peer review) is the author/funder, who has granted medRxiv a license to display the preprint in perpetuity.

It is made available under a CC-BY-NC-ND 4.0 International license .

\begin{tabular}{|c|c|c|c|c|c|c|c|c|c|}
\hline 8 & 38 & 60 & -48 & 18 & 55.7 & -47.2 & 20.9 & $\begin{array}{l}\text { Angular Gyrus, Posterior } \\
\text { Supramarginal Gyrus }\end{array}$ & $\begin{array}{l}\text { Angular Gyrus, Posterior } \\
\text { Supramarginal Gyrus }\end{array}$ \\
\hline 9 & 37 & -44 & -20 & -36 & -45.9 & -19.1 & -31.5 & $\begin{array}{l}\text { Posterior Inferior } \\
\text { Temporal Gyrus, } \\
\text { Posterior Temporal } \\
\text { Fusiform Gyrus } \\
\end{array}$ & $\begin{array}{l}\text { Posterior Inferior } \\
\text { Temporal Gyrus, } \\
\text { Posterior Temporal } \\
\text { Fusiform Gyrus } \\
\end{array}$ \\
\hline 10 & 32 & 20 & -102 & 4 & 16.8 & -101 & 7.44 & Occipital Pole & Occipital Pole \\
\hline 11 & 27 & -62 & -24 & 4 & -63.3 & -23.6 & 8.96 & $\begin{array}{l}\text { Posterior Superior } \\
\text { Temporal Gyrus, Planum } \\
\text { Temporale }\end{array}$ & $\begin{array}{l}\text { Posterior Superior } \\
\text { Temporal Gyrus, Planum } \\
\text { Temporale }\end{array}$ \\
\hline 12 & 26 & -32 & -44 & -42 & -31.6 & -40.5 & -40.9 & Cerebellum & Cerebellum \\
\hline
\end{tabular}

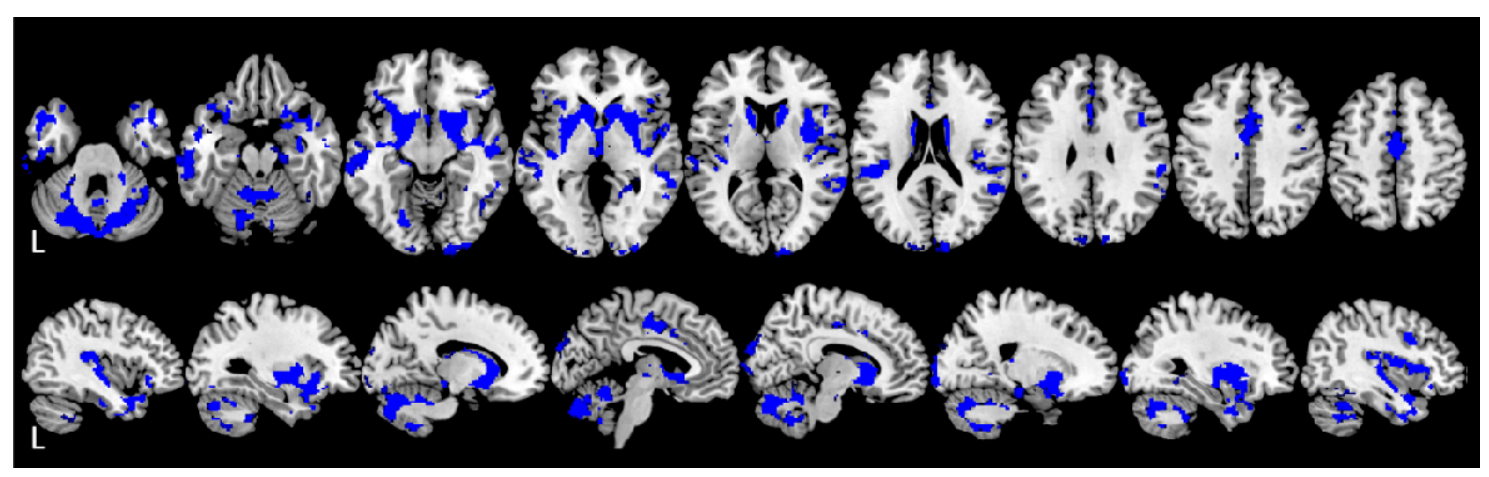

Figure 4. VBM results for significant GM change over time ( $w 1-w 0 ; p_{\text {corrected }}<0.001 ; N=351$ ) in RRMS are shown in blue on a template axial T1W image (top) and sagittal T1W image (bottom). This figure was created using MRIcron (https://www.nitrc.org/projects/mricron) and the implemented 'ch2' template (http://www.bic.mni.mcgill.ca/ServicesAtlases/Colin27). 


\section{Discussion}

The current study used imaging data from the FutureMS cohort, a large longitudinal multicentre cohort of people with recently-diagnosed RRMS in Scotland. The aim of our study was to establish a profile of regional NAWM and GM volume change in the very early-stages of RRMS. In addition, the effects of different imaging analysis approaches were compared.

Widespread NAWM and GM atrophy was observed using both approaches. With the volumetric approach, early-stage RRMS showed brain volume loss in the brainstem, all subcortical regions and the cerebellar GM but not NAWM, over one year. Furthermore, cortical NAWM and GM volume loss over one year was also evident. Specifically, GM and NAWM volume decreased in nearly all temporal, parietal and occipital regions and in about half of frontal regions. Slightly more NAWM regions showed volume decrease in the temporal-parietal lobes and slightly more GM regions showed a volume decrease in the frontal lobe. Additionally, more left frontal GM and NAWM regions showed volume decrease than right frontal regions. With the VBM approach (GM only), most of these subcortical and cortical GM findings in early-stage RRMS were replicated. Large areas of change in GM concentration were observed in temporal and subcortical areas, as well as in the cerebellum and the anterior cingulum, with some smaller areas in the occipital lobe. However, overall, fewer regions of GM change were observed than with the volumetric approach, particularly in the parietal and frontal lobes, without prominent hemispheric differences.

\subsection{Subcortical and brainstem atrophy}

The importance of subcortical neurodegeneration in MS has been recently summarised by Ontaneda et al. (2021), emphasising that atrophy of deep GM structures is common in MS and may be a suitable target for DMT treatment [62]. In this study, we observed prominent subcortical volume change in early RRMS, which is in line with previous studies reporting early-stage subcortical atrophy, specifically in the thalamus and basal ganglia $[14,19,24]$. The thalamus has been suggested to play an important role in MS disease symptomatology, with lower volumes being predictive of clinical worsening [63], even in the early stages [64]. Basal ganglia changes have also frequently been observed and related to clinical change $[65,66]$.

Our study showed that other subcortical regions, such as the amygdala, hippocampus, ventral diencephalon and nucleus accumbens, also show early-stage atrophy. This is in line with previous studies reporting similar subcortical volume changes as well as associations with clinical changes in clinical isolated syndrome (CIS) or later stages of RRMS [66-73]. The brainstem is known to be involved in MS, showing both evidence of WML as well as volume loss, which are associated with clinical symptomatology [74-76]. Here we observed brainstem volume loss in a very early-stage of RRMS, which is corroborated by findings from Eshaghi et al. (2018) [14]. Overall, this may suggest that both the brainstem and subcortical regions play an important role in early-stage neurodegeneration in RRMS.

\subsection{Cerebellar atrophy}

The observed GM volume changes in this study are in line with previous studies reporting early-stage cerebellar atrophy [19] and they are unsurprising as the cerebellum has been shown to play an essential role in both sensorimotor and cognitive dysfunction in MS [77-80]. 
Cerebellar NAWM changes were not observed in this study, which is in line with previous studies reporting absence of cerebellar NAWM volume change in CIS and RRMS [81, 82]. In contrast, some studies do report cerebellar NAWM atrophy in MS [83, 84], however this may be explained by different disease stages being studied as well as study samples lacking a distinction between MS subtypes. Moreover, studies using diffusion tensor imaging (DTI) to explore cerebellar changes in RRMS have observed early-stage NAWM microstructural changes in absence of macrostructural NAWM volume change [85]. This may suggest that microstructural damage is already present in early-stage RRMS, which will go on to develop into macrostructural NAWM atrophy in later stages.

\subsection{Cerebral regional NAWM and GM atrophy}

This study suggests that both regional NAWM and GM are evident in early-stage RRMS in all brain lobes in variable degrees. Using volumetrics, cerebral GM volume loss was observed more prominently in the temporal, parietal and occipital lobes than in the frontal lobe. Similarly, with VBM, prominent GM changes were observed in the temporal, occipital and posterior frontal lobes, but less so in the anterior frontal lobe and parietal lobe. This discrepancy may be explained by the changes within the latter regions being less localised which may have left them undetected by VBM. The early GM changes observed here are partly in line with previous studies showing prominent early changes in the occipital [19], temporal [20,73, 86], parietal (posterior cingulum) [14] and frontal lobe [86]. However, these observations differ from the current results in that they do not report on GM changes in all lobes simultaneously. This is likely explained by differences in methodology [87] (e.g. processing methods, inclusion of healthy controls, design), which is also supported by the discrepancy shown between VBM and volumetric results in this study.

Cerebral NAWM loss has been observed in previous studies [13, 22, 23], but to our knowledge, regional NAWM atrophy has not been investigated before. Similar to regional GM change, we observed widespread cerebral NAWM loss, independent of lesion accumulation, which was most prominent in the temporal, occipital and parietal regions. This suggests that NAWM neurodegeneration is also evident in early-stage RRMS. In comparison with cerebral GM volume loss, cerebral NAWM volume loss was observed in slightly more regions in temporal and parietal lobes, but not in the frontal lobe where more GM regions showed volume loss. This may support the notion that pathological processes underlying GM and NAWM change are at least partly dissociated [88].

More frontal NAWM and GM regions were affected in the left than in the right hemisphere - using the volumetric approach - whereas the temporal, parietal and occipital lobes were symmetrically affected. Although not specifically studied here, we can speculate that cognitive functions commonly associated with the left frontal lobe, such as language, may be more affected in early-stage MS than those associated with the right frontal lobe, such as non-verbal/spatial abilities [89]. Additionally, a left-hemispheric predilection for atrophy in all brain lobes has been observed previously in MS, however only by a small number of studies [90-92]. Furthermore, Preziosa et al (2017) [90] suggest that studies investigating hemispheric asymmetry in damage accumulation, in both ageing and neurological disease, have reported conflicting results. Overall, it remains unclear whether asymmetry of neurodegeneration in MS is evident and further research is required to elucidate this. 
Surprisingly, we also observed a lack of volumetric changes within areas in the frontal lobe associated with sensorimotor functioning, such as in the precentral GM/NAWM and paracentral GM. However, paracentral NAWM volumetric change was indeed observed and the VBM results were also indicative of a small cluster of GM change within the supplemental motor area and precentral gyrus. Previous literature has shown GM volume change in the precentral gyrus in early RRMS compared with healthy controls [93], as well as abnormal iron deposition in the precentral gyrus in later stage MS [94]. This suggests that motor cortex abnormalities are involved in MS as expected, however the lack of volumetric precentral GM changes observed in our study may indicate that widespread motor cortex change over time may not be as fast as in other frontal regions in early RRMS.

\subsection{Volumetry and VBM}

Use of different imaging methods can lead to a difference in results, as was supported by the findings of this study. Although GM change was observed in overlapping areas as well here, there were key differences between the VBM and volumetric output. A volumetric approach like FreeSurfer segments brain regions, allowing for calculating the total amount of voxels within these regions. VBM on the other hand does not require regions to be pre-defined and looks for changes voxel-by-voxel, allowing for detection of local and possibly smaller changes [55]. Furthermore, FSL VBM also uses TFCE which enhances clusters of voxels that show change, increasing focus on changes that occur near each other, even when these changes are small [61]. Volumetrics on the other hand may not detect smaller changes, but it is more sensitive to distributed change across a region, which would be likely missed by VBM.

Further differences in processing steps and statistical methods are also likely to cause outcome differences. For example, VBM treats all data as one group and registers all participants to a common template, which may lead to some individual change being lost. FreeSurfer avoids this by processing participant data separately in their own native space. However, between-subject cortical variability can affect accuracy of atlas-based approaches and may thus bias the volumetric results [95]. Another example is that FSL VBM uses FWE correction for multiple comparisons, whereas we have applied FDR for the volumetric analysis. As FWE is considered to be more stringent than FDR, it is possible that VBM underestimated and FDR overestimated actual change, leading to a difference in results [96].

Specifically, for our RRMS cohort, the difference in results may indicate that the frontal and parietal changes observed with the volumetric approach are more widespread and more variable across participants. On the other hand, the overlapping temporal, occipital and subcortical results, may be indicative of prominent changes within these regions. Overall, both VBM and volumetric approaches have advantages and important limitations that should be taken into consideration when interpreting results.

\subsection{Limitations}

This study has some limitations. Firstly, FutureMS is a multi-centre study involving five different MR systems and two different (although very similar) MR protocols, which may have influenced the results. However, all participants underwent their MR assessment with the same system and protocol at both time points. Pooling of data across centres is important for clinical studies, as it 
allows for drawing conclusions based on larger datasets. Secondly, we have not studied the relationship between atrophy and clinical features in this study. The reason for this is that divergence in clinical disease course is limited over one year in early MS and will develop over a longer timescale. We are therefore initially concentrating on patterns of atrophy between the point of diagnosis and one year and will focus our future research on clinical correlates of atrophy.

\subsection{Conclusion}

Widespread neurodegeneration is observed in early-stage RRMS. This is observed particularly in the brainstem, cerebellar GM, subcortical regions and temporal-occipital GM and NAWM, as assessed by volumetry and VBM. Changes in these regions may provide a suitable target for DMT trials. Our future aims are directed at mapping neurodegenerative patterns across a ten-year time-period in the FutureMS cohort, as well as correlating regional atrophy with evolving clinical disability and other imaging and liquid biomarkers of neurodegeneration available in FutureMS. 


\section{ACKNOWLEDGEMENTS}

With thanks to FutureMS, hosted by Precision Medicine Scotland Innovation Centre (PMS-IC) and funded by a grant from the Chief Scientist Office, Scotland, to PMS-IC and Biogen Idec Ltd Insurance (combined funding under reference Exemplar SMS_IC010). We would like to thank other non-author contributors of the FutureMS consortium as follows: Mark Bastin, Chris Batchelor, Jessie Chang, Peter Connick, Fraser Brown, Tracy Brunton, Yingdi Chen, Shuna Colville, Annette Cooper, Rachel Dakin, Liz Elliott, David Hunt, Aidan Hutchison, Charlotte Jardine, Patrick Kearns, Lucy Kesseler, Michaela Kleynhans, Jen MacFarlane, Bev MacLennan, Sarah-Jane Martin, Daisy Mollison, Mary Monaghan, Scott Semple, Adam Scotson, Amy Stenson, Christine Weaver and Rosie Woodward. With special thanks to all FutureMS participants who have made this study possible.

Additional funding for authors came from the MS Society Edinburgh Centre for MS Research (grant reference 133; RM), Chief Scientist Office - SPRINT MND/MS program (ENY), NHS Lothian Research and Development Office (MJT), and the Row Fogo Charitable Trust (Grant No. BROD.FID3668413; $\mathrm{MVH}$ ). Additional funding for the Edinburgh university $3 T$ MRI Research scanner in RIE is funded by the Wellcome Trust (104916/Z/14/Z), Dunhill Trust (R380R/1114), Edinburgh and Lothians Health Foundation (2012/17), Muir Maxwell Research Fund, Edinburgh Imaging, and University of Edinburgh. 


\section{REFERENCES}

1. Lassmann H (2018) Multiple Sclerosis Pathology. Cold Spring Harb Perspect Med 8:a028936. https://doi.org/10.1101/cshperspect.a028936

2. $\quad$ Reich DS, Lucchinetti CF, Calabresi PA (2018) Multiple Sclerosis. N Engl J Med 378:169-180. https://doi.org/10.1056/NEJMra1401483

3. Wallin MT, Culpepper WJ, Nichols E, et al (2019) Global, regional, and national burden of multiple sclerosis 1990-2016: a systematic analysis for the Global Burden of Disease Study 2016. Lancet Neurol 18:269-285. https://doi.org/10.1016/S1474-4422(18)30443-5

4. MS Society (2018) MS in the UK. https://www.mssociety.org.uk/care-and-support/resourcesand-publications/publications-search/ms-in-the-uk\#

5. Mackenzie IS, Morant S V., Bloomfield GA, et al (2014) Incidence and prevalence of multiple sclerosis in the UK 1990-2010: a descriptive study in the General Practice Research Database. J Neurol Neurosurg Psychiatry 85:76-84. https://doi.org/10.1136/jnnp-2013-305450

6. Kearns PKA, Paton M, O'Neill M, et al (2019) Regional variation in the incidence rate and sex ratio of multiple sclerosis in Scotland 2010-2017: findings from the Scottish Multiple Sclerosis Register. J Neurol 266:2376-2386. https://doi.org/10.1007/s00415-019-09413-x

7. Kister I, Bacon TE, Chamot E, et al (2013) Natural history of multiple sclerosis symptoms. Int J MS Care 15:146-58. https://doi.org/10.7224/1537-2073.2012-053

8. Lublin FD, Reingold SC, Cohen JA, et al (2014) Defining the clinical course of multiple sclerosis: The 2013 revisions. Neurology 83:278-286. https://doi.org/10.1212/WNL.0000000000000560

9. MS Trust (2018) Types of MS. https://www.mstrust. org.uk/about-ms/what-ms/types-ms

10. Thompson AJ, Banwell BL, Barkhof $F$, et al (2018) Diagnosis of multiple sclerosis: 2017 revisions of the McDonald criteria. Lancet Neurol 17:162-173. https://doi.org/10.1016/S1474-4422(17)30470-2

11. McGinley MP, Goldschmidt CH, Rae-Grant AD (2021) Diagnosis and Treatment of Multiple Sclerosis. JAMA 325:765. https://doi.org/10.1001/jama.2020.26858

12. Preziosa P, Rocca MA, Riccitelli GC, et al (2020) Effects of Natalizumab and Fingolimod on Clinical, Cognitive, and Magnetic Resonance Imaging Measures in Multiple Sclerosis. Neurotherapeutics 17:208-217. https://doi.org/10.1007/s13311-019-00781-w

13. Chard DT, Griffin CM, Parker GJM, et al (2002) Brain atrophy in clinically early relapsingremitting multiple sclerosis. Brain 125:327-337. https://doi.org/10.1093/brain/awf025

14. Eshaghi A, Marinescu R V, Young AL, et al (2018) Progression of regional grey matter atrophy in multiple sclerosis. Brain 141:1665-1677. https://doi.org/10.1093/brain/awy088

15. Nygaard GO, Walhovd KB, Sowa P, et al (2015) Cortical thickness and surface area relate to specific symptoms in early relapsing-remitting multiple sclerosis. Mult Scler J 21:402-414. https://doi.org/10.1177/1352458514543811

16. Calabrese M, Atzori M, Bernardi V, et al (2007) Cortical atrophy is relevant in multiple sclerosis at clinical onset. J Neurol 254:1212-1220. https://doi.org/10.1007/s00415-0060503-6

17. Zivadinov R (2001) A longitudinal study of brain atrophy and cognitive disturbances in the early phase of relapsing-remitting multiple sclerosis. J Neurol Neurosurg Psychiatry 70:773780. https://doi.org/10.1136/jnnp.70.6.773

18. Andravizou A, Dardiotis E, Artemiadis A, et al (2019) Brain atrophy in multiple sclerosis: mechanisms, clinical relevance and treatment options. Autoimmun Highlights 10:7. https://doi.org/10.1186/s13317-019-0117-5

19. Dekker I, Schoonheim MM, Venkatraghavan V, et al (2021) The sequence of structural, functional and cognitive changes in multiple sclerosis. Neurolmage Clin 29:102550. https://doi.org/10.1016/j.nicl.2020.102550

20. Radetz A, Koirala N, Krämer J, et al (2020) Gray matter integrity predicts white matter 
medRxiv preprint doi: https://doi.org/10.1101/2021.11.18.21266506; this version posted January 18, 2022. The copyright holder for this preprint (which was not certified by peer review) is the author/funder, who has granted medRxiv a license to display the preprint in perpetuity.

It is made available under a CC-BY-NC-ND 4.0 International license .

network reorganization in multiple sclerosis. Hum Brain Mapp 41:917-927.

https://doi.org/10.1002/hbm.24849

21. Bergsland N, Horakova D, Dwyer MG, et al (2018) Gray matter atrophy patterns in multiple sclerosis: A 10-year source-based morphometry study. Neurolmage Clin 17:444-451. https://doi.org/10.1016/j.nicl.2017.11.002

22. Deppe M, Marinell J, Krämer J, et al (2014) Increased cortical curvature reflects white matter atrophy in individual patients with early multiple sclerosis. Neurolmage Clin 6:475-487. https://doi.org/10.1016/j.nicl.2014.02.012

23. Turner B, Lin X, Calmon G, et al (2003) Cerebral atrophy and disability in relapsing-remitting and secondary progressive multiple sclerosis over four years. Mult Scler J 9:21-27. https://doi.org/10.1191/1352458503ms868oa

24. Deppe M, Krämer J, Tenberge J-G, et al (2016) Early silent microstructural degeneration and atrophy of the thalamocortical network in multiple sclerosis. Hum Brain Mapp 37:1866-1879. https://doi.org/10.1002/hbm.23144

25. Deloire MSA, Ruet A, Hamel D, et al (2011) MRI predictors of cognitive outcome in early multiple sclerosis. Neurology 76:1161-1167. https://doi.org/10.1212/WNL.0b013e318212a8be

26. Horakova D, Dwyer MG, Havrdova E, et al (2009) Gray matter atrophy and disability progression in patients with early relapsing-remitting multiple sclerosis. J Neurol Sci 282:112-119. https://doi.org/10.1016/j.jns.2008.12.005

27. Rudick RA, Lee J-C, Nakamura K, Fisher E (2009) Gray matter atrophy correlates with MS disability progression measured with MSFC but not EDSS. J Neurol Sci 282:106-111. https://doi.org/10.1016/j.jns.2008.11.018

28. Ruggieri S, Petracca M, De Giglio L, et al (2021) A matter of atrophy: differential impact of brain and spine damage on disability worsening in multiple sclerosis. J Neurol. https://doi.org/10.1007/s00415-021-10576-9

29. Haider L, Prados F, Chung K, et al (2021) Cortical involvement determines impairment 30 years after a clinically isolated syndrome. Brain. https://doi.org/10.1093/brain/awab033

30. Marchesi O, Vizzino C, Meani A, et al (2020) Fatigue in multiple sclerosis patients with different clinical phenotypes: a clinical and magnetic resonance imaging study. Eur J Neurol 27:2549-2560. https://doi.org/10.1111/ene.14471

31. Tóth E, Faragó P, Király A, et al (2019) The Contribution of Various MRI Parameters to Clinical and Cognitive Disability in Multiple Sclerosis. Front Neurol 9:.

https://doi.org/10.3389/fneur.2018.01172

32. Hänninen K, Viitala M, Paavilainen T, et al (2020) Thalamic Atrophy Predicts 5-Year Disability Progression in Multiple Sclerosis. Front Neurol 11:

https://doi.org/10.3389/fneur.2020.00606

33. Haider L, Chung K, Birch G, et al (2021) Linear brain atrophy measures in multiple sclerosis and clinically isolated syndromes: a 30-year follow-up. J Neurol Neurosurg Psychiatry jnnp2020-325421. https://doi.org/10.1136/jnnp-2020-325421

34. Kadrnozkova L, Vaneckova M, Sobisek L, et al (2018) Combining clinical and magnetic resonance imaging markers enhances prediction of 12-year employment status in multiple sclerosis patients. J Neurol Sci 388:87-93. https://doi.org/10.1016/j.jns.2018.02.045

35. Khan O, Bao F, Shah M, et al (2012) Effect of disease-modifying therapies on brain volume in relapsing-remitting multiple sclerosis: Results of a five-year brain MRI study. J Neurol Sci 312:7-12. https://doi.org/10.1016/j.jns.2011.08.034

36. Sotirchos ES, Gonzalez-Caldito N, Dewey BE, et al (2020) Effect of disease-modifying therapies on subcortical gray matter atrophy in multiple sclerosis. Mult Scler J 26:312-321. https://doi.org/10.1177/1352458519826364

37. Zivadinov R, Medin J, Khan N, et al (2018) Fingolimod's Impact on MRI Brain Volume Measures in Multiple Sclerosis: Results from MS-MRIUS. J Neuroimaging 28:399-405. 
medRxiv preprint doi: https://doi.org/10.1101/2021.11.18.21266506; this version posted January 18, 2022. The copyright holder for this preprint (which was not certified by peer review) is the author/funder, who has granted medRxiv a license to display the preprint in perpetuity.

It is made available under a CC-BY-NC-ND 4.0 International license .

https://doi.org/10.1111/jon.12518

38. Yousuf F, Dupuy SL, Tauhid S, et al (2017) A two-year study using cerebral gray matter volume to assess the response to fingolimod therapy in multiple sclerosis. J Neurol Sci 383:221-229. https://doi.org/10.1016/j.jns.2017.10.019

39. Zivadinov R, Bergsland N, Hagemeier J, et al (2018) Effect of teriflunomide on gray and white matter brain pathology in multiple sclerosis using volumetric and diffusion-tensor imaging MRI measures. J Neurol Sci 388:175-181. https://doi.org/10.1016/j.jns.2018.03.028

40. Masuda H, Mori M, Hirano S, et al (2019) Relapse numbers and earlier intervention by disease modifying drugs are related with progression of less brain atrophy in patients with multiple sclerosis. J Neurol Sci 403:78-84. https://doi.org/10.1016/j.jns.2019.06.011

41. Sastre-Garriga J, Pareto D, Battaglini M, et al (2020) MAGNIMS consensus recommendations on the use of brain and spinal cord atrophy measures in clinical practice. Nat Rev Neurol 16:171-182. https://doi.org/10.1038/s41582-020-0314-x

42. Kearns PKA, Martin SJ, Chang J, et al (2021) FutureMS Cohort Profile: A Scottish Multi-Centre Inception Cohort Study of Relapsing-Remitting Multiple Sclerosis. medRxiv 2021.04.15.21253274. https://doi.org/10.1101/2021.04.15.21253274

43. Meijboom R, Wiseman SJ, York EN, et al (2021) Rationale and design of the brain magnetic resonance imaging protocol for FutureMS: a longitudinal multi-centre study of newly diagnosed patients with relapsing-remitting multiple sclerosis in Scotland. medRxiv 2021.03.10.21253264. https://doi.org/10.1101/2021.03.10.21253264

44. Jenkinson M, Smith SM (2001) A global optimization method for robust affine registration of brain images. Med Imaging Anal 5:143-156

45. Jenkinson M, Bannister P, Brady M, Smith S (2002) Improved optimization for the robust and accurate linear registration and motion correction of brain images. Neuroimage 17:825-41

46. Smith SM (2002) Fast robust automated brain extraction. Hum Brain Mapp 17:143-55. https://doi.org/10.1002/hbm.10062

47. Yushkevich PA, Piven J, Hazlett HC, et al (2006) User-guided 3D active contour segmentation of anatomical structures: Significantly improved efficiency and reliability. Neuroimage 31:1116-1128. https://doi.org/10.1016/j.neuroimage.2006.01.015

48. Zhan T, Zhan Y, Liu Z, et al (2015) Automatic method for white matter lesion segmentation based on T1-fluid-attenuated inversion recovery images. IET Comput Vis 9:447-455. https://doi.org/10.1049/iet-cvi.2014.0121

49. Chen L, Tong T, Ho CP, et al (2015) Identification of Cerebral Small Vessel Disease Using Multiple Instance Learning. In: Navab N., Hornegger J., Wells W., Frangi A. (eds) Medical Image Computing and Computer-Assisted Intervention -- MICCAI 2015. MICCAI 2015. Lecture Notes in Computer Science, vol 9349. Springer, Cham.

50. Reuter M, Schmansky NJ, Rosas HD, Fischl B (2012) Within-subject template estimation for unbiased longitudinal image analysis. Neuroimage 61:1402-1418.

https://doi.org/10.1016/j. neuroimage.2012.02.084

51. Desikan RS, Ségonne F, Fischl B, et al (2006) An automated labeling system for subdividing the human cerebral cortex on MRI scans into gyral based regions of interest. Neuroimage 31:968-980. https://doi.org/10.1016/j.neuroimage.2006.01.021

52. Douaud G, Smith S, Jenkinson M, et al (2007) Anatomically related grey and white matter abnormalities in adolescent-onset schizophrenia. Brain 130:2375-2386.

https://doi.org/10.1093/brain/awm184

53. Good CD, Johnsrude IS, Ashburner J, et al (2001) A Voxel-Based Morphometric Study of Ageing in 465 Normal Adult Human Brains. Neuroimage 14:21-36. https://doi.org/10.1006/nimg.2001.0786

54. Smith SM, Jenkinson M, Woolrich MW, et al (2004) Advances in functional and structural MR image analysis and implementation as FSL. Neuroimage 23 Suppl 1:S208-19.

https://doi.org/10.1016/j.neuroimage.2004.07.051 
medRxiv preprint doi: https://doi.org/10.1101/2021.11.18.21266506; this version posted January 18, 2022. The copyright holder for this preprint (which was not certified by peer review) is the author/funder, who has granted medRxiv a license to display the preprint in perpetuity.

It is made available under a CC-BY-NC-ND 4.0 International license .

55. Ashburner J, Friston KJ (2000) Voxel-based morphometry--the methods. Neuroimage 11:805821. https://doi.org/10.1006/nimg.2000.0582

56. R Core Team R: A Language and Environment for Statistical Computing

57. Kuznetsova A, Brockhoff PB, Christensen RHB (2017) ImerTest Package: Tests in Linear Mixed Effects Models. J Stat Softw 82:. https://doi.org/10.18637/jss.v082.i13

58. Wickham H (2016) ggplot2: Elegant Graphics for Data Analysis. Springer-Verlag New York

59. Sarkar D (2008) Lattice: Multivariate Data Visualization with R. Springer-Verlag New York

60. Winkler AM, Ridgway GR, Webster MA, et al (2014) Permutation inference for the general linear model. Neuroimage 92:381-97. https://doi.org/10.1016/j.neuroimage.2014.01.060

61. Smith SM, Nichols TE (2009) Threshold-free cluster enhancement: addressing problems of smoothing, threshold dependence and localisation in cluster inference. Neuroimage 44:8398. https://doi.org/10.1016/j.neuroimage.2008.03.061

62. Ontaneda D, Raza PC, Mahajan KR, et al (2021) Deep grey matter injury in multiple sclerosis: A NAIMS consensus statement. Brain. https://doi.org/10.1093/brain/awab132

63. Minagar A, Barnett MH, Benedict RHB, et al (2013) The thalamus and multiple sclerosis: Modern views on pathologic, imaging, and clinical aspects. Neurology 80:210-219. https://doi.org/10.1212/WNL.0b013e31827b910b

64. Nourbakhsh B, Azevedo C, Maghzi A-H, et al (2016) Subcortical grey matter volumes predict subsequent walking function in early multiple sclerosis. J Neurol Sci 366:229-233.

https://doi.org/10.1016/j.jns.2016.04.054

65. Matías-Guiu JA, Cortés-Martínez A, Montero P, et al (2018) Identification of Cortical and Subcortical Correlates of Cognitive Performance in Multiple Sclerosis Using Voxel-Based Morphometry. Front Neurol 9:. https://doi.org/10.3389/fneur.2018.00920

66. Batista S, Zivadinov R, Hoogs M, et al (2012) Basal ganglia, thalamus and neocortical atrophy predicting slowed cognitive processing in multiple sclerosis. J Neurol 259:139-146.

https://doi.org/10.1007/s00415-011-6147-1

67. Morelli ME, Baldini S, Sartori A, et al (2020) Early putamen hypertrophy and ongoing hippocampus atrophy predict cognitive performance in the first ten years of relapsingremitting multiple sclerosis. Neurol Sci 41:2893-2904. https://doi.org/10.1007/s10072-02004395-5

68. Koubiyr I, Deloire M, Coupé $P$, et al (2018) Differential Gray Matter Vulnerability in the 1 Year Following a Clinically Isolated Syndrome. Front Neurol 9:. https://doi.org/10.3389/fneur.2018.00824

69. Koenig KA, Rao SM, Lowe MJ, et al (2019) The role of the thalamus and hippocampus in episodic memory performance in patients with multiple sclerosis. Mult Scler J 25:574-584. https://doi.org/10.1177/1352458518760716

70. Planche V, Koubiyr I, Romero JE, et al (2018) Regional hippocampal vulnerability in early multiple sclerosis: Dynamic pathological spreading from dentate gyrus to $\langle\mathrm{scp}\rangle \mathrm{CA}</ \mathrm{scp}\rangle 1$. Hum Brain Mapp 39:1814-1824. https://doi.org/10.1002/hbm.23970

71. Lorefice L, Fenu G, Mammoliti R, et al (2021) Event-related potentials and deep grey matter atrophy in multiple sclerosis: Exploring the possible associations with cognition. Mult Scler Relat Disord 49:102785. https://doi.org/10.1016/j.msard.2021.102785

72. Batista S, D'Almeida OC, Afonso A, et al (2017) Impairment of social cognition in multiple sclerosis: Amygdala atrophy is the main predictor. Mult Scler J 23:1358-1366.

https://doi.org/10.1177/1352458516680750

73. Fujimori J, Fujihara K, Wattjes M, Nakashima I (2021) Patterns of cortical grey matter thickness reduction in multiple sclerosis. Brain Behav 11:. https://doi.org/10.1002/brb3.2050

74. Kerbrat A, Gros C, Badji A, et al (2020) Multiple sclerosis lesions in motor tracts from brain to cervical cord: spatial distribution and correlation with disability. Brain 143:2089-2105. https://doi.org/10.1093/brain/awaa162

75. Fujimori J, Fujihara K, Ogawa R, et al (2020) Patterns of regional brain volume loss in multiple 
medRxiv preprint doi: https://doi.org/10.1101/2021.11.18.21266506; this version posted January 18, 2022. The copyright holder for this preprint (which was not certified by peer review) is the author/funder, who has granted medRxiv a license to display the preprint in perpetuity.

It is made available under a CC-BY-NC-ND 4.0 International license .

sclerosis: a cluster analysis. J Neurol 267:395-405. https://doi.org/10.1007/s00415-01909595-4

76. Bellenberg B, Schneider R, Weiler F, et al (2015) Cervical cord area is associated with infratentorial grey and white matter volume predominantly in relapsing-remitting multiple sclerosis: A study using semi-automated cord volumetry and voxel-based morphometry. Mult Scler Relat Disord 4:264-272. https://doi.org/10.1016/j.msard.2015.04.003

77. Argento O, Spanò B, Pisani V, et al (2020) Dual-Task Performance in Multiple Sclerosis' Patients: Cerebellum Matters? Arch Clin Neuropsychol. https://doi.org/10.1093/arclin/acaa089

78. Odom AD, Richmond SB, Fling BW (2021) White Matter Microstructure of the Cerebellar Peduncles Is Associated with Balance Performance during Sensory Re-Weighting in People with Multiple Sclerosis. The Cerebellum 20:92-100. https://doi.org/10.1007/s12311-02001190-y

79. Ruggieri S, Bharti K, Prosperini L, et al (2020) A Comprehensive Approach to Disentangle the Effect of Cerebellar Damage on Physical Disability in Multiple Sclerosis. Front Neurol 11:. https://doi. org/10.3389/fneur.2020.00529

80. Kalron A, Menascu S, Givon U, et al (2020) Is the walk ratio a window to the cerebellum in multiple sclerosis? A structural magnetic resonance imaging study. Eur J Neurol 27:454-460. https://doi.org/10.1111/ene.14119

81. Anderson V, Fisniku L, Altmann D, et al (2009) MRI measures show significant cerebellar gray matter volume loss in multiple sclerosis and are associated with cerebellar dysfunction. Mult Scler J 15:811-817. https://doi.org/10.1177/1352458508101934

82. Kugler A V., Deppe M (2018) Non-lesional cerebellar damage in patients with clinically isolated syndrome: DTI measures predict early conversion into clinically definite multiple sclerosis. Neurolmage Clin 19:633-639. https://doi.org/10.1016/j.nicl.2018.04.028

83. Preziosa P, Rocca MA, Pagani E, et al (2020) Two-year regional grey and white matter volume changes with natalizumab and fingolimod. J Neurol Neurosurg Psychiatry 91:493-502. https://doi.org/10.1136/jnnp-2019-322439

84. Ramasamy DP, Benedict RHB, Cox JL, et al (2009) Extent of cerebellum, subcortical and cortical atrophy in patients with MS. J Neurol Sci 282:47-54.

https://doi.org/10.1016/j.jns.2008.12.034

85. Schneider R, Genç E, Ahlborn C, et al (2019) Temporal Dynamics of Diffusion Metrics in Early Multiple Sclerosis and Clinically Isolated Syndrome: A 2-Year Follow-Up Tract-Based Spatial Statistics Study. Front Neurol 10:. https://doi.org/10.3389/fneur.2019.01165

86. Sailer M (2003) Focal thinning of the cerebral cortex in multiple sclerosis. Brain 126:17341744. https://doi.org/10.1093/brain/awg175

87. Singh S, Tench CR, Tanasescu R, Constantinescu CS (2020) Localised Grey Matter Atrophy in Multiple Sclerosis and Clinically Isolated Syndrome-A Coordinate-Based Meta-Analysis, Meta-Analysis of Networks, and Meta-Regression of Voxel-Based Morphometry Studies. Brain Sci 10:798. https://doi.org/10.3390/brainsci10110798

88. Calabrese M, Favaretto A, Martini V, Gallo P (2013) Grey matter lesions in MS. Prion 7:20-27. https://doi.org/10.4161/pri.22580

89. Esteves M, Lopes SS, Almeida A, et al (2020) Unmasking the relevance of hemispheric asymmetries-Break on through (to the other side). Prog Neurobiol 192:101823. https://doi.org/10.1016/j.pneurobio.2020.101823

90. Preziosa P, Pagani E, Mesaros S, et al (2017) Progression of regional atrophy in the left hemisphere contributes to clinical and cognitive deterioration in multiple sclerosis: A 5-year study. Hum Brain Mapp 38:5648-5665. https://doi.org/10.1002/hbm.23755

91. Prinster A, Quarantelli M, Orefice $G$, et al (2006) Grey matter loss in relapsing-remitting multiple sclerosis: A voxel-based morphometry study. Neuroimage 29:859-867.

https://doi.org/10.1016/j.neuroimage.2005.08.034 
medRxiv preprint doi: https://doi.org/10.1101/2021.11.18.21266506; this version posted January 18, 2022. The copyright holder for this preprint

(which was not certified by peer review) is the author/funder, who has granted medRxiv a license to display the preprint in perpetuity.

It is made available under a CC-BY-NC-ND 4.0 International license.

92. Achiron A, Chapman J, Tal S, et al (2013) Superior temporal gyrus thickness correlates with cognitive performance in multiple sclerosis. Brain Struct Funct 218:943-950.

https://doi.org/10.1007/s00429-012-0440-3

93. Pietroboni AM, Colombi A, Carandini T, et al (2020) Low CSF $\beta$-amyloid levels predict early regional grey matter atrophy in multiple sclerosis. Mult Scler Relat Disord 39:101899. https://doi. org/10.1016/j.msard.2019.101899

94. Rumzan R, Wang J, Zeng C, et al (2013) Iron deposition in the precentral grey matter in patients with multiple sclerosis: A quantitative study using susceptibility-weighted imaging. Eur J Radiol 82:e95-e99. https://doi.org/10.1016/j.ejrad.2012.09.006

95. Mikhael S, Hoogendoorn C, Valdes-Hernandez M, Pernet C (2018) A critical analysis of neuroanatomical software protocols reveals clinically relevant differences in parcellation schemes. Neuroimage 170:348-364. https://doi.org/10.1016/j.neuroimage.2017.02.082

96. Nichols K (2007) False Discovery Rate procedures. In: Statistical Parametric Mapping. Elsevier, pp 246-252 


\section{SUPPLEMENT}

Supplement Table 1. Future MS MRI parameters for protocol A and B

\begin{tabular}{|c|c|c|c|c|c|c|c|c|c|c|c|c|c|c|c|c|}
\hline \multirow[b]{2}{*}{ Sequence } & \multicolumn{12}{|c|}{ A. PROTOCOL A } & \multirow{2}{*}{\multicolumn{4}{|c|}{ 3D FLAIR }} \\
\hline & & $\underline{\mathrm{T} 1-\mathrm{w}}$ & ghted & & & $\underline{T 2-1}$ & eighted & & & $\underline{2 \mathrm{D}}$ & LAIR & & & & & \\
\hline Site & EDI1 & GLA & DUN & ABN & EDI1 & GLA & DUN & ABN & EDI1 & GLA & DUN & ABN & EDI1 & GLA & DUN & ABN \\
\hline Mode & $3 \mathrm{D}$ & $3 \mathrm{D}$ & $3 \mathrm{D}$ & $3 \mathrm{D}$ & $2 \mathrm{D}$ & $2 \mathrm{D}$ & $2 \mathrm{D}$ & $3 \mathrm{D}$ & $2 \mathrm{D}$ & $2 \mathrm{D}$ & $2 \mathrm{D}$ & $2 \mathrm{D}$ & $3 \mathrm{D}$ & $3 \mathrm{D}$ & $3 \mathrm{D}$ & $3 \mathrm{D}$ \\
\hline $\mathrm{FOV}(\mathrm{mm})$ & 256 & 256 & 256 & 240 & 220 & 220 & 220 & 256 & 250 & 250 & 250 & 250 & 256 & $\begin{array}{c}256 x \\
248\end{array}$ & $\begin{array}{c}256 \\
x \\
248 \\
\end{array}$ & 256 \\
\hline Orientation & Sag & Sag & Sag & Sag & $\mathrm{Ax}$ & $\mathrm{Ax}$ & $\mathrm{Ax}$ & Sag & $\mathrm{Ax}$ & $\mathrm{Ax}$ & $\mathrm{Ax}$ & $\mathrm{Ax}$ & Sag & Sag & Sag & Sag \\
\hline $\mathrm{TR}(\mathrm{ms})$ & 2530 & 2500 & 2500 & 3000 & 6000 & 6160 & 6160 & 2500 & 9500 & 9500 & 9500 & 11000 & 5000 & 5000 & 5000 & 8000 \\
\hline TE (ms) & 3.37 & 2.26 & 2.26 & 3.9 & 96 & 96 & 96 & 310 & 124 & 124 & 124 & 125 & 715 & 393 & 393 & 347 \\
\hline $\mathrm{TI}(\mathrm{ms})$ & 1100 & 1100 & 1100 & 1048 & - & - & - & - & 2400 & 2400 & 2400 & 2800 & 1800 & 1800 & 1800 & 2400 \\
\hline $\begin{array}{l}\text { Flip angle } \\
\text { (deg) }\end{array}$ & 7 & 7 & 7 & 8 & 150 & 150 & 150 & - & 150 & 150 & 150 & 120 & - & - & - & - \\
\hline Gap (mm) & - & - & - & - & 1.2 & 1.2 & 1.2 & - & 0 & 0 & 0 & 1 & - & - & - & - \\
\hline Matrix (mm) & $\begin{array}{c}256 \\
\times \\
256 \\
\end{array}$ & $\begin{array}{c}256 \\
\times \\
256 \\
\end{array}$ & $\begin{array}{c}256 \\
\times \\
256 \\
\end{array}$ & $\begin{array}{c}240 \\
\times \\
240 \\
\end{array}$ & $\begin{array}{c}320 x \\
320\end{array}$ & $\begin{array}{c}320 \\
\times \\
314 \\
\end{array}$ & $\begin{array}{c}314 x \\
314\end{array}$ & $\begin{array}{c}256 x \\
256\end{array}$ & $\begin{array}{c}256 \\
x \\
256 \\
\end{array}$ & $\begin{array}{c}256 \\
\times \\
256\end{array}$ & $\begin{array}{c}256 \\
x \\
256 \\
\end{array}$ & $\begin{array}{c}252 x \\
226\end{array}$ & $\begin{array}{c}256 \\
x \\
256 \\
\end{array}$ & $\begin{array}{c}256 x \\
248\end{array}$ & $\begin{array}{c}256 \\
x \\
248 \\
\end{array}$ & $\begin{array}{c}256 x \\
256\end{array}$ \\
\hline $\begin{array}{l}\text { Voxel size } \\
\text { (mm) }\end{array}$ & $\begin{array}{l}1 \times 1 \\
\times 1\end{array}$ & $\begin{array}{c}1 \times 1 \\
\times 1\end{array}$ & $\begin{array}{c}1 \times 1 \\
\times 1\end{array}$ & $\begin{array}{c}1 \times 1 \\
\times 1\end{array}$ & $\begin{array}{c}0.7 \times \\
0.7 \times \\
4\end{array}$ & $\begin{array}{c}0.7 \times \\
0.7 \times \\
4\end{array}$ & $\begin{array}{c}0.7 \times \\
0.7 \times \\
4 \\
\end{array}$ & $1 \times 1 \times 2$ & $\begin{array}{l}1 \times 1 \\
\times 3\end{array}$ & $\begin{array}{c}1 \times 1 \\
\times 3\end{array}$ & $\begin{array}{c}1 \times 1 \\
\times 3\end{array}$ & $\begin{array}{c}1 \times 1.1 \\
\times 3\end{array}$ & $\begin{array}{c}1 \times 1 \\
\times 1\end{array}$ & $\begin{array}{l}1 \times 1 \\
\times 1.3\end{array}$ & $\begin{array}{l}1 \times 1 \\
\times 1.3\end{array}$ & $\begin{array}{c}1 \times 1 \\
\times 2\end{array}$ \\
\hline $\begin{array}{l}\text { Slices } \\
\text { reconstructed }\end{array}$ & 176 & 176 & 176 & 160 & 33 & 33 & 33 & 176 & 60 & 60 & 60 & 29 & 176 & 176 & 176 & 176 \\
\hline $\begin{array}{l}\text { Acq. Time } \\
\text { (m:ss) }\end{array}$ & $6: 03$ & $5: 59$ & $5: 59$ & $5: 38$ & $1: 26$ & $1: 03$ & $1: 03$ & $3: 42$ & $7: 38$ & $7: 38$ & $7: 38$ & $5: 08$ & $7: 22$ & $5: 32$ & $5: 32$ & $8: 32$ \\
\hline
\end{tabular}

\begin{tabular}{|c|c|c|c|c|}
\hline \multicolumn{5}{|c|}{ B. PROTOCOL B } \\
\hline Sequence & T1-weighted (MPRAGE) & T2-weighted dual echo (FSE) & 2D FLAIR (PROPELLER) & 3D FLAIR (SPACE) \\
\hline Mode & $3 \mathrm{D}$ & $2 \mathrm{D}$ & $2 \mathrm{D}$ & $3 \mathrm{D}$ \\
\hline FOV (mm) & 256 & 250 & 250 & 256 \\
\hline Orientation & Sagittal & Axial & Axial & Sagittal \\
\hline $\mathrm{TR}(\mathrm{ms})$ & 2500 & 3630 & 9500 & 5000 \\
\hline TE (ms) & 2.26 & $9.6,96$ & 120 & 393 \\
\hline $\mathrm{TI}(\mathrm{ms})$ & 1100 & - & 2400 & 1800 \\
\hline $\begin{array}{l}\text { Flip angle } \\
\text { (deg) }\end{array}$ & 7 & 150 & 150 & - \\
\hline Gap (mm) & - & 0 & 0 & - \\
\hline Matrix (mm) & $256 \times 256$ & $384 \times 384$ & $256 \times 256$ & $256 \times 256$ \\
\hline $\begin{array}{l}\text { Voxel size } \\
(\mathrm{mm})\end{array}$ & $1 \times 1 \times 1$ & $0.7 \times 0.7 \times 3$ & $1 \times 1 \times 3$ & $1 \times 1 \times 1$ \\
\hline Slices & 176 & 60 & 60 & 176 \\
\hline $\begin{array}{l}\text { Acceleration } \\
\text { factor (in- } \\
\text { plane } \times \text { slice) }\end{array}$ & $2 \times 1$ & $3 \times 1$ & $2 \times 1$ & $2 \times 1$ \\
\hline $\begin{array}{l}\text { Acq. Time } \\
\text { (m:ss) }\end{array}$ & $5: 59$ & 4:01 & $4: 47$ & $6: 52$ \\
\hline
\end{tabular}

FLAIR = fluid attenuated inversion recovery; EDI1 = Edinburgh site 1; GLA = Glasgow; DUN = Dundee; ABN = Aberdeen; FOV = field of view; TR = repetition time; $\mathrm{TE}=$ echo time; $\mathrm{TI}$ = inversion time; $\mathrm{deg}=$ degree; acq. = acquisition; sag = sagittal; $\mathrm{Ax}=$ axial

Supplement table 2. Regional GM and NAWM volume results for change over time (w1-w0) as assessed with a linear mixed-effects model, corrected for age, sex, imaging site, DMT status at w1 and WML change. Mean and SD are shown for raw volumes (r-ICV), without covariate correction.

\begin{tabular}{|c|c|c|c|c|c|c|c|c|}
\hline & & B & $\mathrm{df}$ & $\mathrm{t}$ & p-value $\mathrm{Cl} 2.5 . \mathrm{Cl} 97.5$ & Mean wC & Mean w1 & 1 SD w0 SD w1 \\
\hline \multirow{5}{*}{$\begin{array}{l}\frac{\text { 응 }}{0} \\
\frac{\pi}{\pi} \\
\frac{1}{2} \\
\frac{}{4}\end{array}$} & GM caudal anterior cingulate $L$ & -0.0427 & 0.0080304 & -5.3715 & $0.0000-0.0584-0.0271$ & 0.0012 & 0.0011 & 0.00030 .0003 \\
\hline & GM caudal anterior cingulate $R$ & -0.0227 & 0.0075306 & -3.0389 & $0.0026-0.0373-0.0080$ & 0.0013 & 0.0013 & 0.00030 .0003 \\
\hline & GM caudal middle frontal $\mathrm{L}$ & -0.0339 & 0.0132304 & -2.5684 & $0.0107-0.0598-0.0080$ & 0.0041 & 0.0041 & 0.00070 .0007 \\
\hline & GM caudal middle frontal $\mathrm{R}$ & -0.0277 & 0.0132304 & -2.1009 & $0.0365-0.0536-0.0018$ & 0.0040 & 0.0040 & 0.00060 .0006 \\
\hline & GM frontal pole L & -0.0287 & 0.0206303 & -1.3920 & $0.1650-0.06910 .0118$ & 0.0006 & 0.0006 & 0.00010 .0001 \\
\hline
\end{tabular}




\begin{tabular}{|c|c|c|c|c|c|c|}
\hline GM frontal pole $R$ & -0.03920 .0198303 & -1.9744 & $0.0492-0.0781-0.0002$ & 0.0007 & 0.0007 & 0.00010 .0001 \\
\hline GM lateral orbitofrontal L & -0.06910 .0169306 & -4.0946 & $0.0001-0.1022-0.0360$ & 0.0050 & 0.0050 & 0.00040 .0004 \\
\hline GM lateral orbitofrontal $\mathrm{R}$ & -0.02780 .0200305 & -1.3862 & $0.1667-0.06710 .0116$ & 0.0048 & 0.0048 & 0.00040 .0004 \\
\hline GM medial orbitofrontal L & -0.06210 .0221303 & -2.8136 & $0.0052-0.1054-0.0188$ & 0.0034 & 0.0033 & 0.00030 .0003 \\
\hline GM medial orbitofrontal $R$ & -0.01310 .0218304 & -0.6006 & $\begin{array}{llll}0.5485 & -0.0560 & 0.0298\end{array}$ & 0.0035 & 0.0035 & 0.00030 .0003 \\
\hline GM paracentral L & -0.01930 .0169303 & -1.1375 & $0.2562-0.05250 .0140$ & 0.0023 & 0.0023 & 0.00030 .0003 \\
\hline GM paracentral $R$ & -0.03020 .0161303 & -1.8725 & $0.0621-0.0618 \quad 0.0015$ & 0.0026 & 0.0026 & 0.00030 .0003 \\
\hline GM pars opercularis L & -0.03910 .0102303 & -3.8325 & $0.0002-0.0592-0.0191$ & 0.0031 & 0.0030 & 0.00050 .0005 \\
\hline GM pars opercularis $R$ & -0.04300 .0116304 & -3.6992 & $0.0003-0.0658-0.0202$ & 0.0025 & 0.0025 & 0.00030 .0004 \\
\hline GM pars orbitalis L & -0.03660 .0153305 & -2.3976 & $0.0171-0.0665-0.0066$ & 0.0016 & 0.0016 & 0.00020 .0002 \\
\hline GM pars orbitalis $R$ & -0.06130 .0147304 & -4.1741 & $0.0000-0.0901-0.0325$ & 0.0018 & 0.0018 & 0.00020 .0002 \\
\hline GM pars triangularis $\mathrm{L}$ & -0.03550 .0117305 & -3.0242 & $0.0027-0.0586-0.0125$ & 0.0024 & 0.0024 & 0.00030 .0003 \\
\hline GM pars triangularis $R$ & -0.04140 .0113305 & -3.6681 & $0.0003-0.0635-0.0192$ & 0.0028 & 0.0028 & 0.00040 .0004 \\
\hline GM precentral L & -0.01060 .0180304 & -0.5870 & $\begin{array}{llll}0.5576 & -0.0458 & 0.0247\end{array}$ & 0.0088 & 0.0088 & 0.00090 .0009 \\
\hline GM precentral $\mathrm{R}$ & -0.00420 .0174305 & -0.2426 & $0.8085-0.0383 \quad 0.0299$ & 0.0087 & 0.0086 & 0.00090 .0009 \\
\hline GM rostral anterior cingulate $\mathrm{L}$ & -0.04280 .0114303 & -3.7544 & $0.0002-0.0652-0.0204$ & 0.0017 & 0.0017 & 0.00030 .0003 \\
\hline GM rostral anterior cingulate $R$ & -0.01940 .0105306 & -1.8410 & $0.0666-0.0400 \quad 0.0013$ & 0.0013 & 0.0013 & 0.00020 .0002 \\
\hline GM rostral middle frontal L & -0.04900 .0142302 & -3.4591 & $0.0006-0.0768-0.0212$ & 0.0101 & 0.0100 & 0.00110 .0011 \\
\hline GM rostral middle frontal $\mathrm{R}$ & -0.02890 .0147303 & -1.9585 & $0.0511-0.0578 \quad 0.0001$ & 0.0102 & 0.0102 & 0.00110 .0012 \\
\hline GM superior frontal L & -0.06260 .0194303 & -3.2324 & $0.0014-0.1005-0.0246$ & 0.0146 & 0.0146 & 0.00150 .0015 \\
\hline GM superior frontal $R$ & -0.03440 .0187304 & -1.8369 & $\begin{array}{llll}0.0672 & -0.0711 & 0.0024\end{array}$ & 0.0140 & 0.0140 & 0.00140 .0014 \\
\hline NAWM caudal anterior cingulate $L$ & -0.07370 .0136304 & -5.4291 & $0.0000-0.1003-0.0470$ & 0.0017 & 0.0017 & 0.00020 .0002 \\
\hline NAWM caudal anterior cingulate $R$ & -0.08470 .0136304 & -6.2084 & $0.0000-0.1115-0.0579$ & 0.0017 & 0.0017 & 0.00020 .0002 \\
\hline NAWM caudal middle frontal L & -0.01760 .0089306 & -1.9799 & $0.0486-0.0350-0.0002$ & 0.0042 & 0.0042 & 0.00050 .0005 \\
\hline NAWM caudal middle frontal $R$ & -0.02560 .0095305 & -2.7089 & $0.0071-0.0442-0.0071$ & 0.0038 & 0.0038 & 0.00060 .0005 \\
\hline NAWM frontal pole $L$ & -0.01380 .0244303 & -0.5670 & $0.5711-0.0618 \quad 0.0341$ & 0.0002 & 0.0002 & 0.00000 .0000 \\
\hline NAWM frontal pole $R$ & 0.00170 .0201306 & 0.0848 & $0.9325-0.03770 .0411$ & 0.0002 & 0.0002 & 0.00000 .0000 \\
\hline NAWM lateral orbitofrontal L & -0.07310 .0111304 & -6.5999 & $0.0000-0.0949-0.0514$ & 0.0044 & 0.0043 & 0.00040 .0004 \\
\hline NAWM lateral orbitofrontal $R$ & -0.01350 .0227304 & -0.5952 & $0.5522-0.0580 \quad 0.0310$ & 0.0044 & 0.0044 & 0.00040 .0004 \\
\hline NAWM medial orbitofrontal L & -0.02400 .0216306 & -1.1105 & $0.2676-0.06650 .0184$ & 0.0024 & 0.0024 & 0.00030 .0003 \\
\hline NAWM medial orbitofrontal $R$ & -0.03260 .0216305 & -1.5076 & $0.1327-0.07510 .0099$ & 0.0024 & 0.0024 & 0.00020 .0002 \\
\hline NAWM paracentral L & -0.04890 .0140303 & -3.5001 & $0.0005-0.0764-0.0215$ & 0.0025 & 0.0025 & 0.00030 .0003 \\
\hline NAWM paracentral $R$ & -0.03810 .0135302 & -2.8307 & $0.0050-0.0645-0.0117$ & 0.0029 & 0.0029 & 0.00040 .0004 \\
\hline NAWM pars opercularis L & -0.02590 .0094304 & -2.7548 & $0.0062-0.0444-0.0075$ & 0.0023 & 0.0022 & 0.00040 .0004 \\
\hline NAWM pars opercularis $R$ & -0.02900 .0086305 & -3.3554 & $0.0009-0.0459-0.0120$ & 0.0021 & 0.0021 & 0.00030 .0003 \\
\hline NAWM pars orbitalis $L$ & -0.02410 .0175304 & -1.3774 & $0.1694-0.05850 .0103$ & 0.0007 & 0.0007 & 0.00010 .0001 \\
\hline NAWM pars orbitalis $R$ & -0.03940 .0177303 & -2.2231 & $0.0269-0.0741-0.0046$ & 0.0008 & 0.0008 & 0.00010 .0001 \\
\hline NAWM pars triangularis $L$ & -0.01720 .0105306 & -1.6397 & $0.1021-0.0378 \quad 0.0034$ & 0.0019 & 0.0019 & 0.00030 .0003 \\
\hline NAWM pars triangularis $R$ & -0.01000 .0110305 & -0.9101 & $0.3635-0.03150 .0116$ & 0.0021 & 0.0021 & 0.00030 .0003 \\
\hline NAWM precentral L & -0.02630 .0150304 & -1.7472 & $0.0816-0.0558 \quad 0.0032$ & 0.0084 & 0.0084 & 0.00090 .0009 \\
\hline NAWM precentral $R$ & -0.02050 .0131304 & -1.5673 & $0.1181-0.04610 .0052$ & 0.0084 & 0.0084 & 0.00090 .0009 \\
\hline NAWM rostral anterior cingulate $L$ & -0.03050 .0175306 & -1.7413 & $0.0826-0.06490 .0039$ & 0.0017 & 0.0017 & 0.00020 .0002 \\
\hline NAWM rostral anterior cingulate $R$ & -0.03310 .0155304 & -2.1380 & $0.0333-0.0634-0.0027$ & 0.0012 & 0.0012 & 0.00020 .0002 \\
\hline NAWM rostral middle frontal $\mathrm{L}$ & -0.03060 .0098304 & -3.1093 & $0.0021-0.0499-0.0113$ & 0.0082 & 0.0081 & 0.00090 .0009 \\
\hline NAWM rostral middle frontal $R$ & -0.01930 .0099304 & -1.9525 & $0.0518-0.03860 .0001$ & 0.0084 & 0.0083 & 0.00100 .0010 \\
\hline NAWM superior frontal $\mathrm{L}$ & -0.03460 .0138305 & -2.5064 & $0.0127-0.0618-0.0075$ & 0.0116 & 0.0115 & 0.00120 .0012 \\
\hline NAWM superior frontal $R$ & -0.03090 .0130306 & -2.3843 & $0.0177-0.0564-0.0055$ & 0.0112 & 0.0112 & 0.00120 .0012 \\
\hline GM banks sts $\mathbf{L}$ & -0.03800 .0093305 & -4.1049 & $0.0001-0.0562-0.0198$ & 0.0016 & 0.0016 & 0.00030 .0003 \\
\hline GM banks sts $R$ & -0.03270 .0123304 & -2.6696 & $0.0080-0.0568-0.0087$ & 0.0014 & 0.0014 & 0.00020 .0002 \\
\hline GM entorhinal L & -0.00480 .0186301 & -0.2566 & $0.7977-0.0412 \quad 0.0317$ & 0.0013 & 0.0013 & 0.00020 .0002 \\
\hline GM entorhinal $R$ & -0.02730 .0186301 & -1.4654 & $0.1439-0.0638 \quad 0.0093$ & 0.0013 & 0.0013 & 0.00020 .0002 \\
\hline GM fusiform $\mathrm{L}$ & -0.05200 .0128304 & -4.0555 & $0.0001-0.0772-0.0268$ & 0.0063 & 0.0063 & 0.00070 .0007 \\
\hline GM fusiform $\mathrm{R}$ & -0.03180 .0115304 & -2.7566 & $0.0062-0.0544-0.0091$ & 0.0062 & 0.0061 & 0.00070 .0007 \\
\hline GM inferior temporal L & -0.04690 .0133302 & -3.5354 & $0.0005-0.0729-0.0209$ & 0.0072 & 0.0072 & 0.00090 .0008 \\
\hline GM inferior temporal $\mathrm{R}$ & -0.02850 .0109306 & -2.6200 & $0.0092-0.0499-0.0071$ & 0.0070 & 0.0070 & 0.00090 .0008 \\
\hline
\end{tabular}




\begin{tabular}{|c|c|c|c|c|c|c|}
\hline GM middle temporal $\mathrm{L}$ & -0.05480 .0102306 & -5.3575 & $0.0000-0.0748-0.0347$ & 0.0072 & 0.0072 & 0.00090 .0009 \\
\hline GM middle temporal $\mathrm{R}$ & -0.05360 .0117305 & -4.5676 & $0.0000-0.0766-0.0306$ & 0.0079 & 0.0079 & 0.00080 .0008 \\
\hline GM parahippocampal L & -0.07320 .0129303 & -5.6699 & $0.0000-0.0986-0.0479$ & 0.0014 & 0.0014 & 0.00020 .0002 \\
\hline GM parahippocampal $R$ & -0.03570 .0135306 & -2.6519 & $0.0084-0.0621-0.0093$ & 0.0013 & 0.0013 & 0.00020 .0002 \\
\hline GM superior temporal L & -0.06210 .0126305 & -4.9259 & $0.0000-0.0869-0.0374$ & 0.0081 & 0.0081 & 0.00080 .0008 \\
\hline GM superior temporal $R$ & -0.05380 .0145303 & -3.7182 & $0.0002-0.0822-0.0254$ & 0.0077 & 0.0076 & 0.00070 .0007 \\
\hline GM temporal pole $\mathrm{L}$ & -0.06930 .0224304 & -3.0976 & $0.0021-0.1133-0.0254$ & 0.0016 & 0.0016 & 0.00020 .0002 \\
\hline GM temporal pole $R$ & -0.02200 .0183305 & -1.2051 & $0.2291-0.0578 \quad 0.0138$ & 0.0016 & 0.0016 & 0.00020 .0002 \\
\hline GM transverse temporal L & -0.05840 .0121305 & -4.8309 & $0.0000-0.0822-0.0347$ & 0.0008 & 0.0008 & 0.00010 .0001 \\
\hline GM transverse temporal $\mathrm{R}$ & -0.05820 .0149305 & -3.9144 & $0.0001-0.0874-0.0290$ & 0.0006 & 0.0006 & 0.00010 .0001 \\
\hline NAWM banks sts $L$ & -0.03050 .0063306 & -4.8228 & $0.0000-0.0429-0.0181$ & 0.0018 & 0.0018 & 0.00040 .0004 \\
\hline NAWM banks sts $R$ & -0.03500 .0074306 & -4.7167 & $0.0000-0.0496-0.0204$ & 0.0018 & 0.0018 & 0.00030 .0003 \\
\hline NAWM entorhinal L & -0.04490 .0142305 & -3.1629 & $0.0017-0.0728-0.0171$ & 0.0005 & 0.0005 & 0.00010 .0001 \\
\hline NAWM entorhinal $R$ & -0.04400 .0168305 & -2.6141 & $0.0094-0.0770-0.0110$ & 0.0005 & 0.0005 & 0.00010 .0001 \\
\hline NAWM fusiform L & -0.09340 .0106304 & -8.8314 & $0.0000-0.1142-0.0727$ & 0.0042 & 0.0042 & 0.00050 .0005 \\
\hline NAWM fusiform $R$ & -0.08490 .0100305 & -8.4850 & $0.0000-0.1045-0.0652$ & 0.0041 & 0.0040 & 0.00050 .0005 \\
\hline NAWM inferior temporal $L$ & -0.05900 .0100305 & -5.8886 & $0.0000-0.0787-0.0394$ & 0.0041 & 0.0041 & 0.00050 .0005 \\
\hline NAWM inferior temporal $\mathrm{R}$ & -0.05020 .0088306 & -5.6877 & $0.0000-0.0675-0.0329$ & 0.0039 & 0.0039 & 0.00050 .0005 \\
\hline NAWM middle temporal L & -0.04560 .0105302 & -4.3298 & $0.0000-0.0663-0.0250$ & 0.0034 & 0.0034 & 0.00050 .0005 \\
\hline NAWM middle temporal $R$ & -0.05430 .0112306 & -4.8671 & $0.0000-0.0762-0.0324$ & 0.0039 & 0.0039 & 0.00040 .0004 \\
\hline NAWM parahippocampal L & -0.06430 .0193303 & -3.3345 & $0.0010-0.1021-0.0264$ & 0.0009 & 0.0009 & 0.00010 .0001 \\
\hline NAWM parahippocampal R & -0.06850 .0135304 & -5.0885 & $0.0000-0.0950-0.0421$ & 0.0009 & 0.0009 & 0.00010 .0001 \\
\hline NAWM superior temporal L & -0.05210 .0106305 & -4.8927 & $0.0000-0.0730-0.0312$ & 0.0049 & 0.0049 & 0.00060 .0006 \\
\hline NAWM superior temporal R & -0.05880 .0130304 & -4.5178 & $0.0000-0.0844-0.0333$ & 0.0041 & 0.0041 & 0.00040 .0005 \\
\hline NAWM temporal pole L & -0.09780 .0316304 & -3.0908 & $\mathbf{0 . 0 0 2 2}-0.1599-0.0357$ & 0.0004 & 0.0004 & 0.00010 .0001 \\
\hline NAWM temporal pole $\mathrm{R}$ & -0.08560 .0283302 & -3.0283 & $0.0027-0.1410-0.0301$ & 0.0004 & 0.0004 & 0.00010 .0001 \\
\hline NAWM transverse temporal L & -0.05810 .0177301 & -3.2807 & $0.0012-0.0929-0.0234$ & 0.0005 & 0.0005 & 0.00010 .0001 \\
\hline NAWM transverse temporal R & -0.07360 .0189305 & -3.8929 & $0.0001-0.1108-0.0365$ & 0.0004 & 0.0004 & 0.00010 .0001 \\
\hline GM inferior parietal L & -0.05720 .0095305 & -6.0062 & $0.0000-0.0759-0.0385$ & 0.0078 & 0.0077 & 0.00110 .0011 \\
\hline GM inferior parietal $R$ & -0.03180 .0105306 & -3.0272 & $0.0027-0.0524-0.0112$ & 0.0093 & 0.0093 & 0.00120 .0012 \\
\hline GM isthmus cingulate $L$ & -0.03790 .0113305 & -3.3378 & $0.0009-0.0601-0.0156$ & 0.0017 & 0.0016 & 0.00020 .0002 \\
\hline GM isthmus cingulate $R$ & -0.03290 .0113304 & -2.9048 & $0.0039-0.0552-0.0107$ & 0.0015 & 0.0015 & 0.00020 .0002 \\
\hline GM postcentral L & -0.02800 .0176303 & -1.5875 & $0.1134-0.06250 .0066$ & 0.0064 & 0.0064 & 0.00070 .0007 \\
\hline GM postcentral $R$ & -0.02130 .0182304 & -1.1726 & $\begin{array}{lll}0.2419 & -0.0569 & 0.0143\end{array}$ & 0.0061 & 0.0061 & 0.00070 .0007 \\
\hline GM posterior cingulate $L$ & -0.05330 .0115304 & -4.6249 & $0.0000-0.0759-0.0307$ & 0.0020 & 0.0020 & 0.00020 .0002 \\
\hline GM posterior cingulate $R$ & -0.03050 .0126302 & -2.4247 & $0.0159-0.0551-0.0058$ & 0.0020 & 0.0020 & 0.00030 .0003 \\
\hline GM precuneus $\mathrm{L}$ & -0.05880 .0140306 & -4.2146 & $0.0000-0.0862-0.0314$ & 0.0063 & 0.0062 & 0.00060 .0006 \\
\hline GM precuneus $R$ & -0.03540 .0145305 & -2.4337 & $0.0155-0.0639-0.0068$ & 0.0065 & 0.0065 & 0.00060 .0006 \\
\hline GM superior parietal L & -0.05440 .0153306 & -3.5492 & $0.0004-0.0846-0.0243$ & 0.0087 & 0.0087 & 0.00100 .0010 \\
\hline GM superior parietal $R$ & -0.02920 .0167304 & -1.7514 & $0.0809-0.06180 .0035$ & 0.0086 & 0.0085 & 0.00100 .0010 \\
\hline GM supramarginal $\mathrm{L}$ & -0.04550 .0116306 & -3.9271 & $0.0001-0.0682-0.0228$ & 0.0073 & 0.0073 & 0.00090 .0009 \\
\hline GM supramarginal $R$ & -0.03770 .0115304 & -3.2801 & $0.0012-0.0602-0.0151$ & 0.0067 & 0.0066 & 0.00080 .0008 \\
\hline NAWM inferior parietal L & -0.05680 .0083306 & -6.8408 & $0.0000-0.0732-0.0405$ & 0.0060 & 0.0059 & 0.00090 .0009 \\
\hline NAWM inferior parietal $R$ & -0.03940 .0079305 & -5.0073 & $0.0000-0.0548-0.0239$ & 0.0069 & 0.0069 & 0.00090 .0009 \\
\hline NAWM isthmus cingulate $L$ & -0.08050 .0139305 & -5.7708 & $0.0000-0.1078-0.0531$ & 0.0023 & 0.0023 & 0.00030 .0003 \\
\hline NAWM isthmus cingulate $R$ & -0.08460 .0128304 & -6.5868 & $0.0000-0.1098-0.0594$ & 0.0021 & 0.0020 & 0.00030 .0003 \\
\hline NAWM postcentral L & -0.06990 .0189304 & -3.6904 & $0.0003-0.1071-0.0327$ & 0.0045 & 0.0044 & 0.00050 .0005 \\
\hline NAWM postcentral $R$ & -0.05370 .0193305 & -2.7883 & $0.0056-0.0915-0.0159$ & 0.0044 & 0.0044 & 0.00050 .0005 \\
\hline NAWM posterior cingulate $L$ & -0.09190 .0135305 & -6.8279 & $0.0000-0.1183-0.0654$ & 0.0027 & 0.0027 & 0.00030 .0003 \\
\hline NAWM posterior cingulate $R$ & -0.10840 .0136303 & -7.9875 & $0.0000-0.1350-0.0817$ & 0.0026 & 0.0026 & 0.00030 .0003 \\
\hline NAWM precuneus $L$ & -0.10550 .0121304 & -8.6864 & $0.0000-0.1293-0.0817$ & 0.0056 & 0.0056 & 0.00070 .0007 \\
\hline NAWM precuneus $R$ & -0.10590 .0106304 & -10.0093 & $0.0000-0.1267-0.0851$ & 0.0059 & 0.0059 & 0.00080 .0008 \\
\hline NAWM superior parietal L & -0.04370 .0108305 & -4.0599 & $0.0001-0.0649-0.0226$ & 0.0075 & 0.0074 & 0.00080 .0008 \\
\hline NAWM superior parietal $R$ & -0.03200 .0094306 & -3.4224 & $0.0007-0.0504-0.0137$ & 0.0072 & 0.0072 & 0.00080 .0008 \\
\hline NAWM supramarginal L & -0.02290 .0092306 & -2.4891 & $0.0133-0.0410-0.0048$ & 0.0055 & 0.0055 & 0.00070 .0007 \\
\hline
\end{tabular}


medRxiv preprint doi: https://doi.org/10.1101/2021.11.18.21266506; this version posted January 18, 2022. The copyright holder for this preprint

(which was not certified by peer review) is the author/funder, who has granted medRxiv a license to display the preprint in perpetuity.

It is made available under a CC-BY-NC-ND 4.0 International license.

\begin{tabular}{|c|c|c|c|c|c|c|}
\hline & NAWM supramarginal $R$ & $-0.02410 .0080305-3.0080$ & $0.0028-0.0398-0.0084$ & 0.0054 & 0.0054 & 0.00070 .0007 \\
\hline \multirow{16}{*}{ 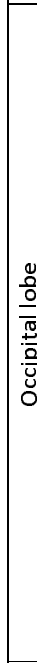 } & GM cuneus $L$ & $-0.03590 .0094306 \quad-3.8099$ & $0.0002-0.0543-0.0174$ & 0.0020 & 0.0020 & 0.00040 .0003 \\
\hline & GM cuneus $R$ & $-0.04160 .0114306 \quad-3.6361$ & $0.0003-0.0641-0.0191$ & 0.0022 & 0.0022 & 0.00030 .0003 \\
\hline & GM lateral occipital L & $-0.06590 .0143304 \quad-4.6146$ & $0.0000-0.0939-0.0379$ & 0.0081 & 0.0080 & 0.00090 .0009 \\
\hline & GM lateral occipital $R$ & $-0.02970 .0122305 \quad-2.4401$ & $0.0153-0.0537-0.0058$ & 0.0083 & 0.0083 & 0.00100 .0010 \\
\hline & GM lingual L & $-0.04190 .0106303 \quad-3.9378$ & $0.0001-0.0628-0.0210$ & 0.0043 & 0.0043 & 0.00060 .0006 \\
\hline & GM lingual $R$ & $-0.03700 .0104306-3.5429$ & $0.0005-0.0574-0.0165$ & 0.0046 & 0.0046 & 0.00060 .0006 \\
\hline & GM pericalcarine $L$ & $-0.03020 .0141303 \quad-2.1360$ & $0.0335-0.0580-0.0024$ & 0.0014 & 0.0014 & 0.00030 .0003 \\
\hline & GM pericalcarine $R$ & $-0.04250 .0149304 \quad-2.8549$ & $0.0046-0.0718-0.0133$ & 0.0015 & 0.0015 & 0.00030 .0003 \\
\hline & NAWM cuneus $L$ & $-0.03550 .0140303 \quad-2.5362$ & $0.0117-0.0630-0.0080$ & 0.0016 & 0.0016 & 0.00030 .0003 \\
\hline & NAWM cuneus $R$ & $-0.00190 .0149303 \quad-0.1298$ & $\begin{array}{lll}0.8968 & -0.0313 & 0.0274\end{array}$ & 0.0016 & 0.0016 & 0.00030 .0003 \\
\hline & NAWM lateral occipital L & $-0.06910 .0147305 \quad-4.7133$ & $0.0000-0.0979-0.0403$ & 0.0060 & 0.0060 & 0.00070 .0007 \\
\hline & NAWM lateral occipital $R$ & 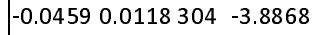 & $0.0001-0.0691-0.0227$ & 0.0062 & 0.0062 & 0.00080 .0008 \\
\hline & NAWM lingual L & $-0.11920 .0153304 \quad-7.7776$ & $0.0000-0.1493-0.0891$ & 0.0033 & 0.0033 & 0.00050 .0005 \\
\hline & NAWM lingual $R$ & $-0.08130 .0135305-6.0041$ & $0.0000-0.1078-0.0547$ & 0.0035 & 0.0035 & 0.00060 .0006 \\
\hline & NAWM pericalcarine $L$ & $-0.16220 .0130305-12.5033$ & $0.0000-0.1876-0.1367$ & 0.0020 & 0.0019 & 0.00040 .0004 \\
\hline & NAWM pericalcarine $R$ & $-0.13860 .0122304-11.3367$ & $0.0000-0.1626-0.1146$ & 0.0020 & 0.0020 & 0.00040 .0005 \\
\hline \multirow{4}{*}{$\begin{array}{l}\frac{\sigma}{\vec{J}} \\
\stackrel{\omega}{\underline{\omega}}\end{array}$} & GM insula L & $-0.04660 .0172303 \quad-2.7129$ & $0.0071-0.0802-0.0129$ & 0.0045 & 0.0045 & 0.00040 .0004 \\
\hline & GM insula $R$ & $-0.04080 .0193305 \quad-2.1147$ & $0.0353-0.0787-0.0029$ & 0.0045 & 0.0045 & 0.00040 .0004 \\
\hline & NAWM insula L & $-0.03680 .0147303 \quad-2.5082$ & $0.0127-0.0656-0.0080$ & 0.0061 & 0.0061 & 0.00050 .0005 \\
\hline & NAWM insula $R$ & $-0.01780 .0188304 \quad-0.9494$ & $0.3432-0.0547 \quad 0.0190$ & 0.0060 & 0.0060 & 0.00050 .0005 \\
\hline
\end{tabular}

